\title{
Effect of Mean Velocity-to-Critical Velocity Ratios on Bed Topography and Incipient Motion in a Meandering Channel: Experimental Investigation
}

\author{
Nargess Moghaddassi ${ }^{1}$, Seyed Habib Musavi-Jahromi ${ }^{2}, * \mathbb{B}$, Mohammad Vaghefi ${ }^{3}$ and Amir Khosrojerdi ${ }^{1}$ \\ 1 Department of Water Engineering, Science and Research Branch, Islamic Azad University, \\ Tehran 1477893855, Iran; nargess.moghaddassi@srbiau.ac.ir (N.M.); khosrojerdi@srbiau.ac.ir (A.K.) \\ 2 Faculty of Water Sciences Engineering, Shahid Chamran University of Ahwaz, Ahwaz 6135783151, Iran \\ 3 Department of Civil Engineering, Persian Gulf University, Bushehr 7516913817, Iran; vaghefi@pgu.ac.ir \\ * Correspondence: h-mousavi@srbiau.ac.ir; Tel.: +98-9127126513
}

check for

updates

Citation: Moghaddassi, N.; Musavi-Jahromi, S.H.; Vaghefi, M.; Khosrojerdi, A. Effect of Mean Velocity-to-Critical Velocity Ratios on Bed Topography and Incipient Motion in a Meandering Channel: Experimental Investigation. Water 2021, 13, 883. https://doi.org/ $10.3390 / w 13070883$

Academic Editor: Alistair Borthwick

Received: 5 February 2021

Accepted: 19 March 2021

Published: 24 March 2021

Publisher's Note: MDPI stays neutral with regard to jurisdictional claims in published maps and institutional affiliations.

Copyright: (c) 2021 by the authors. Licensee MDPI, Basel, Switzerland. This article is an open access article distributed under the terms and conditions of the Creative Commons Attribution (CC BY) license (https:// creativecommons.org/licenses/by/ $4.0 /)$.

\begin{abstract}
As 180-degree meanders are observed in abundance in nature, a meandering channel with two consecutive 180-degree bends was designed and constructed to investigate bed topography variations. These two 180-degree mild bends are located between two upstream and downstream straight paths. In this study, different mean velocity-to-critical velocity ratios have been tested at the upstream straight path to determine the meander's incipient motion. To this end, bed topography variations along the meander and the downstream straight path were addressed for different mean velocity-to-critical velocity ratios. In addition, the upstream bend's effect on the downstream bend was investigated. Results indicated that the maximum scour depth at the downstream bend increased as a result of changing the mean velocity-to-critical velocity ratio from 0.8 to $0.84,0.86,0.89,0.92,0.95$, and 0.98 by, respectively, 1.5, 2.5, 5, 10, 12, and 26 times. Moreover, increasing the ratio increased the maximum sedimentary height by $3,10,23,48,49$, and 56 times. The upstream bend's incipient motion was observed for the mean velocity-to-critical velocity ratio of 0.89 , while the downstream bend's incipient motion occurred for the ratio of 0.78 .
\end{abstract}

Keywords: 180-degree bend; sediment transport; clear water; meandering channel; scour

\section{Introduction}

Seldom can rivers in nature be observed to be following a straight path, and they tend to flow in meandrous or braided patterns. The presence of meanders [1,2] in river paths is a factor involved in creating scour or sedimentation. On the other hand, hydrodynamic forces are applied onto sediment particles on the river bed through the river path. An increase in flow velocity augments the hydrodynamic forces. Thus, if the flow force can overcome bed sediments' weight force, this process will result in sediment transport [3] and bed topography variations. As a result of the interaction between the longitudinal and secondary flows in bent paths and the generation of helical flows [4], the flow's force becomes more complex. This leads to more sediment transport than that occurring in upstream straight paths. Hence, studying and understanding sediment transport and sediment incipient motion mechanisms in bends require more investigation than studying those in straight channels.

A great number of research studies have so far been conducted with regard to incipient motion in rivers due to its importance, and the following research studies may be referred to as instances:

Shields [5] defined the incipient motion based on the sediment transport rate. Inspired by Shields' studies, Dey and Papanicolaou [6] carried out advanced studies to determine the incipient motion under the influence of a steady flow. Kramer [7] discussed the sediment incipient motion particles based on the apparent particle motion condition. 
Bagnold [8] described the incipient motion based on the uplift force. Neill [9] defined the incipient motion based on the critical velocity. The critical velocity is the flow velocity under the sediment particles' incipient motion condition on the channel bed. Lavelle and Mofjeld [10] examined the concept of critical stress under incipient motion conditions in a turbulent flow. The results obtained from their studies suggest that there is no specific definition of a process that leads to scouring because the researcher discerns the time and the extent of sediment transport as both effective and important, which can be enough to bring about much uncertainty about this phenomenon. Yen and Lee [11] investigated bed topography variations in a 180-degree mild bend under unsteady flow conditions. Their research refers to the significant effect of the secondary flow and velocity at the outer bend on bed topography variations. Dey and Debnath [12] evaluated the effect of bed slope on sediment particle motion. After analytical and experimental investigations and the application of different static angles for sediments, they concluded that the critical shear stress decreased with an increase in bed slope. $\mathrm{Xu}$ and Bai [13] conducted an empirical study on bed topography formation in alluvial and meandering rivers with different radii. To study the role of different sinusoidal shapes of the channels on the flow variations and the bed morphology in meandering rivers, they carried out their experiments in curved channels with fixed walls and a movable bed. Mohtar [14] studied the effect of turbulent fluctuations and vortices on the sediment incipient motion. Their results implied a constant Shields parameter in the flow region having a rigid bed. Having addressed the flow velocity direction in meandering channels, Liu et al. [15] developed a model for calculating the mean 2D flow velocity. Safari et al. [16] carried out an experimental investigation of the incipient motion in a straight channel with different cross sections, including trapezoidal, rectangular, circular, U-shaped, and V-shaped ones. Their results indicated that rectangular and V-shaped cross sections, respectively, require the minimum and the maximum velocity and shear stress to reach sediment incipient motion. Núñez-González et al. [17] measured the data related to the end of a meandering path in a river. Their data analysis demonstrated that grain size variations are dominant under nearly incipient motion conditions. Every size fraction goes in motion in a limited flow range, given the association between boundary shear stress and fields of bedload transport. Qin et al. [18] investigated the secondary flow effect on bed topography variations and cohesive sediment transport in Yangtze's meandering path. Taye and Kumar [19] conducted an experimental study of bed morphological characteristics in a sinuous rectangular channel under the influence of downward seepage. They used the Reynolds shear stress distribution to determine the sediment's radial motion along this meandering channel. Azarisamani et al. [20] worked on the effect of rigid vegetation on bed topography variations and flow velocity in a meandering channel.

Most studies on the incipient motion have thus far been conducted in totally straight or single-bended paths, as noted above. Moreover, since there have been no comprehensive experimental studies on the incipient motion condition in meanders thus far, this research's main objective is to find sediments' incipient motion in a meandering channel experimentally. To this end, a meandering channel with two consecutive 180-degree mild bends in-between straight upstream and downstream reaches was designed and constructed by the authors. Investigations of the effect of different mean velocity-to-critical velocity ratios [21] at the upstream straight reach on bed topography variations along the meander, the effect of the upstream bend's geometry on bed topography variations in the downstream bend, and the effect of the downstream straight end on the upstream bend are amongst the other objectives of this study.

\section{Materials and Methods}

In order to carry out the intended experiments in the laboratory, the meandering channel with two consecutive bends, as shown in Figure 1, was designed, implemented, and constructed for the first time in Iran [22]. This channel comprises an 8-m-long path upstream and one downstream, connected by two consecutive 180-degree bends (Figure 1a) 
with inner and outer radii of 300 and $400 \mathrm{~cm}$. The channel wall is $80 \mathrm{~cm}$ high and $100 \mathrm{~cm}$ wide, and the ratio of the bend radius (R) to channel width (B) is equal to $R / B=3.5$ (Figure 1b). According to the categorization developed by Leschziner and Rodi [23], this bend qualifies as a mild bend.

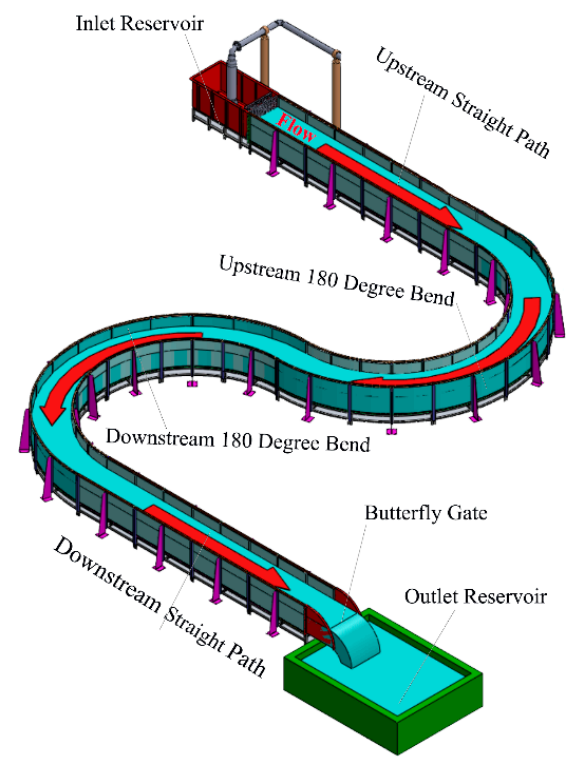

(a)

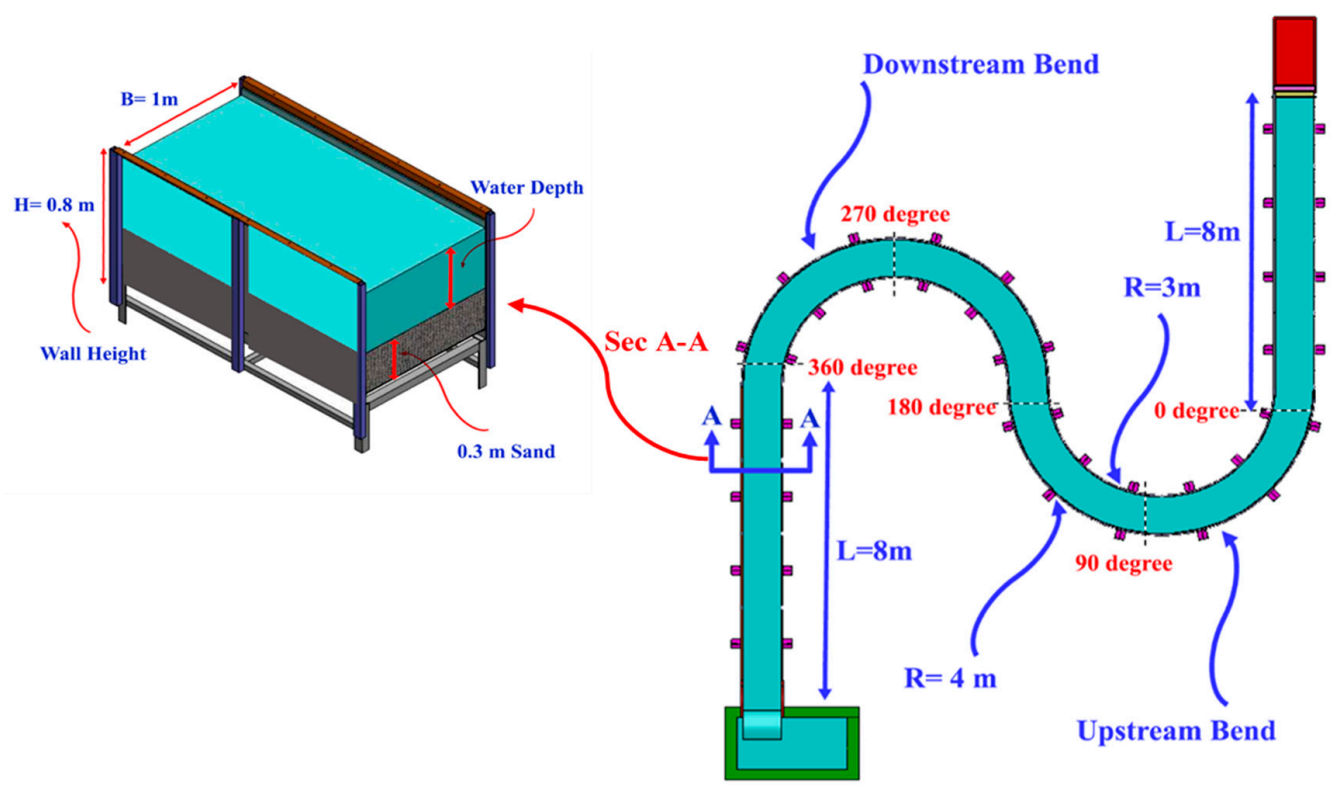

(b)

Figure 1. Schematic illustration of (a) 3D view and (b) plan and cross-sectional views of the meandering channel.

As Raudkivi and Ettema [24] recommended, the mean particle diameter $\left(\mathrm{d}_{50}\right)$ must be larger than $0.07 \mathrm{~cm}$ to prevent dunes formation [25]. Hence, the channel bed is covered with a 30 -cm-thick layer of silica sand with $\mathrm{d}_{50}=0.185 \mathrm{~cm}$ and a standard deviation of 1.2. Given the criterion suggested by Chiew [26], the tests were considered to run for $4 \mathrm{~h}$. To supply the required water to the channel, side reservoir tanks with a capacity of $30 \mathrm{~m}^{3}$ have been used. The discharge capacity produced by the pump system was constantly maintained as $70 \mathrm{Lit} / \mathrm{s}$ when running the tests. The ultrasonic Aktek (Type: TFM3100-F1) flowmeter 
with a precision of $\pm 1 \%$ was utilized for determining the discharge. The flow depth at the upstream straight path was considered to range from 17 to $21.8 \mathrm{~cm}$ to provide flow velocity variations under incipient motion conditions. Mean velocity-to-critical velocity ratios $(\mathrm{U} / \mathrm{Uc})$ were determined from 0.75 to 0.98 at the upstream straight path, considering the formula proposed in Neill [9] and a constant discharge. Therefore, the Froude number falls within the range of 0.22 to 0.31 and is subcritical in different tests. Table 1 presents the characterization and conditions of different tests introduced in the paper.

Table 1. Test characterization and conditions.

\begin{tabular}{ccccccccc}
\hline Test No. & Test $\mathbf{1}$ & Test 2 & Test 3 & Test 4 & Test 5 & Test 6 & Test 7 & Test 8 \\
\hline U/Uc & 0.75 & 0.80 & 0.84 & 0.86 & 0.89 & 0.92 & 0.95 & 0.98 \\
Water depth (cm) & 21.8 & 20.5 & 19.5 & 19.0 & 18.5 & 18.0 & 17.5 & 17.0 \\
Depth-width ratio & 0.22 & 0.21 & 0.20 & 0.19 & 0.19 & 0.18 & 0.18 & 0.17 \\
\hline
\end{tabular}

In these tests, the Leica laser bathometer (DISTO-D510) with a precision of $0.1 \mathrm{~cm}$ in $200 \mathrm{~m}$ was used for bed topography data collection. The mesh grid for data collection covered the area from the beginning of the first bend to the end of the second bend at $1-\mathrm{cm}$ intervals at the width and specific angles. Given the very small number of bed topography variations at the beginning of the upstream bend, the collection was conducted at every 10 degrees, while it was collected at every five degrees at the end of the bend. Moreover, given the large number of variations in the downstream bend, data collection was performed every two degrees for more precise results. Figure 2 illustrates an instance of the mesh for the collected data for $\mathrm{U} / \mathrm{Uc}=0.98$. In this figure, $\theta$ represents different angles along the meander, and $\mathrm{x}$ is the distance of the collection points at channel width.

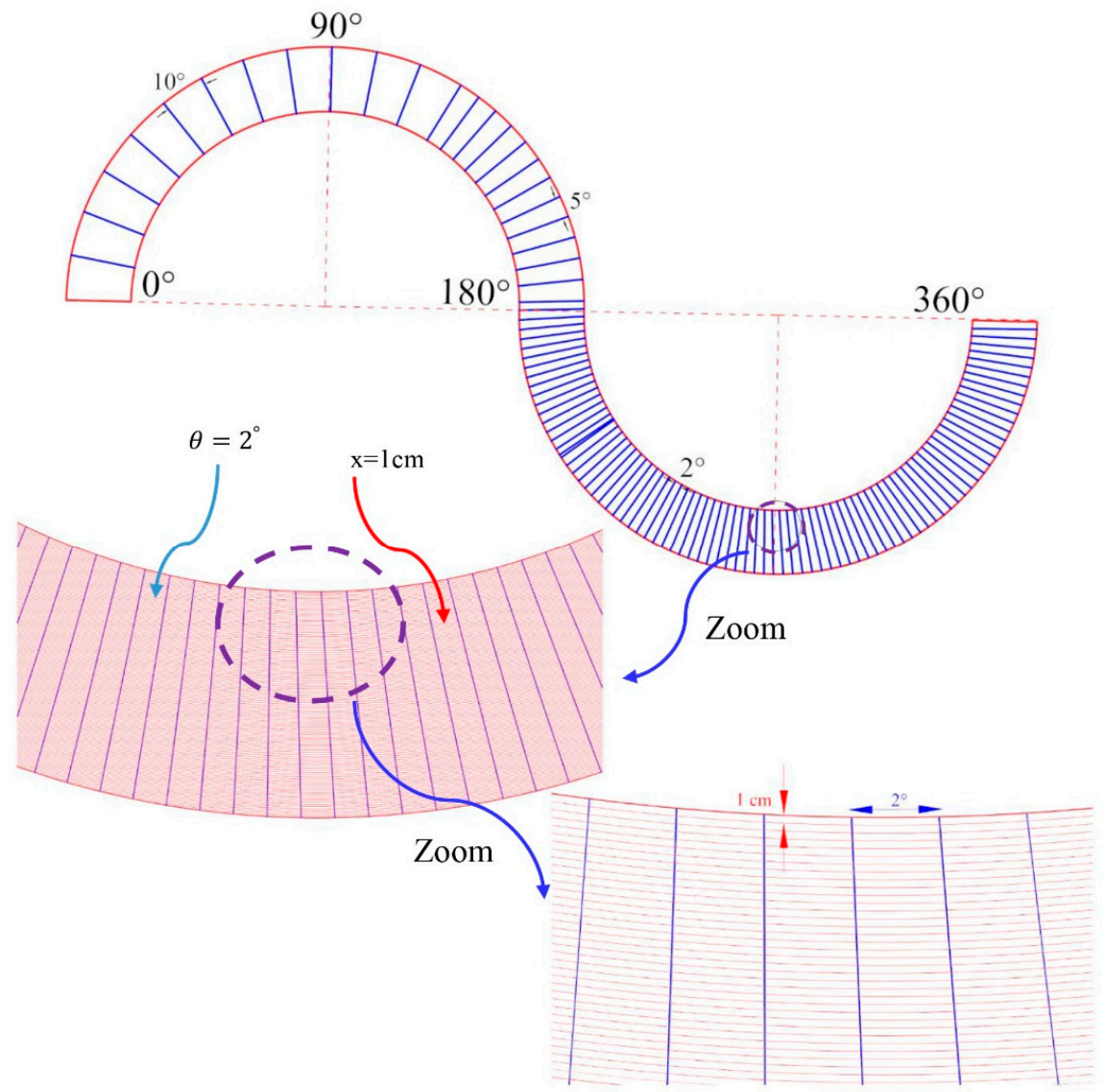

Figure 2. An instance of the mesh grid for data collection in mean velocity-to-critical velocity ratio $(\mathrm{U} / \mathrm{Uc})=0.98$ test. 
The hypotheses considered for this study are as follows:

- The downstream bend's presence influences bed topography variations and changes in incipient motion conditions along the upstream bend;

- In the downstream bend, in addition to the downstream straight path's influencing the incipient motion conditions, the upstream bend geometry also affects bed topography variations in the downstream bend;

- There are more bed topography variations created in the downstream bend than in the upstream bend;

- The maximum sedimentation height occurs near the inner bank, and the maximum scour depth occurs near the outer bank.

\section{Results}

\subsection{Bed Topography Variations}

This section aims to provide the incipient motion condition for upstream and downstream bends regarding variations in U/Uc at the upstream straight path. Bed topography variations in tests with $\mathrm{U} / \mathrm{Uc}_{\mathrm{c}}$ ranging from 0.75 to 0.86 are presented in Figure 3. One important note considered here is the effect of the upstream bend geometry and the flow passing through it on bed topography variations at the downstream bend. As it may be observed in Figure 3a $\left(\mathrm{U} / \mathrm{Uc}_{\mathrm{c}}=0.75\right)$, bed topography remained unchanged from the beginning of the upstream bend to the end of the downstream bend. Neither of the bends has reached the incipient motion condition yet. In Figure 3b, the onset of bed topography variations occurred at the downstream bend after changing U/Uc from 0.75 to 0.8 . Moreover, the incipient motion at the downstream bend occurred as $\mathrm{U} / \mathrm{Uc}=0.78$ at the upstream straight path. As shown in this figure, the maximum scour depth, equivalent to $3.2 \mathrm{~d}_{50}(0.6 \mathrm{~cm})$, occurred at the 275 -degree angle.

The maximum sedimentation height also developed insignificantly at the 200-degree angle. In Figure $3 c$, the maximum scour depth and sedimentation height occurred at $4.8 \mathrm{~d}_{50}$ $(0.9 \mathrm{~cm})$ at the 275 -degree angle and $3.2 \mathrm{~d}_{50}(0.6 \mathrm{~cm})$ at the 195-degree angle. With the increase in $\mathrm{U} / \mathrm{Uc}$ from 0.8 to 0.84 , there was no significant change in bed topography at the upstream bend; however, the maximum scour depth and sedimentation height at the downstream bend, respectively, increased by 1.5 and 3 times.

As it may be observed in Figure $3 \mathrm{~d}(\mathrm{U} / \mathrm{Uc}=0.86)$, the secondary flow at the upstream bend was not yet strong enough to alter bed topography; however, topography variations were observed within 200- to 300-degree angles in the downstream bend, as in previous cases. The maximum scour and sedimentation also occurred for $8 \mathrm{~d}_{50}$ at 275 degrees and $11.4 \mathrm{~d}_{50}$ at 200 degrees. In fact, by increasing the $\mathrm{U} / \mathrm{Uc}$ range of $0.84-0.86$, there was an increase by factors of 1.5 and 3.5 in the maximum scour and sedimentation, respectively. The flow velocity grew at the downstream bend given the decline in the water height under the downstream straight path's effect. Hence, bed topography underwent some changes. The flow at the upstream bend was directed toward the inner bank in the first half. When the flow reached the second half of the bend, it was diverted first toward the mid-channel and then toward the outer bank. With the augmentation of the secondary flow strength at the sections toward the end of the upstream bend, the scouring onset also covered the beginning of the downstream bend for this U/Uc. There was a conversion at the junction between the two bends. Therefore, the outer bank at the upstream bend became the inner bank at the downstream bend, which caused a change of direction in the secondary flows.

A comparison between different conditions illustrated in Figure 3 suggests that the maximum sedimentation height for each of these cases occurred from 195 to 200 degrees at a distance equal to $5 \%$ of the inner bank's channel width. This may be attributed to the sediment transport's direction toward the inner bank under the secondary flow pattern's influence. Furthermore, considering the secondary flow direction, the flow's shedding over the sediments, and the generation of a downflow, the maximum scour occurred in the second half of the downstream bend around the 275-degree angle and mid-channel in every test. 


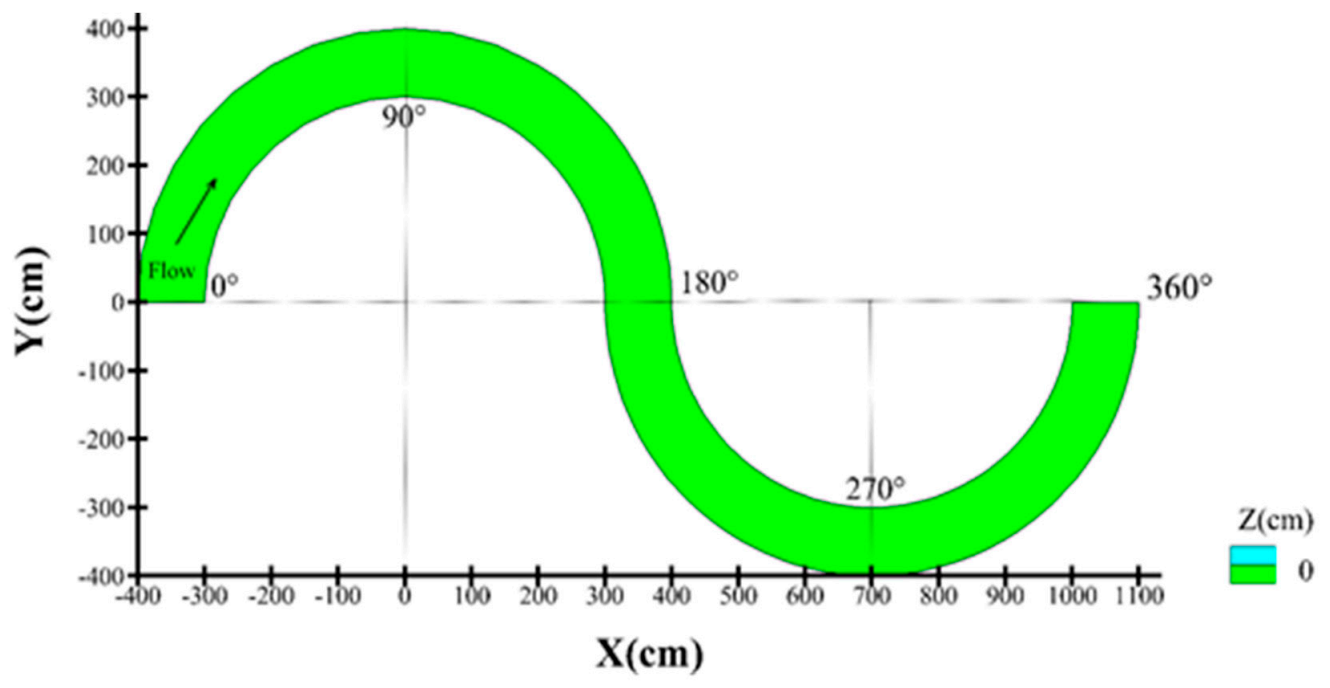

(a)

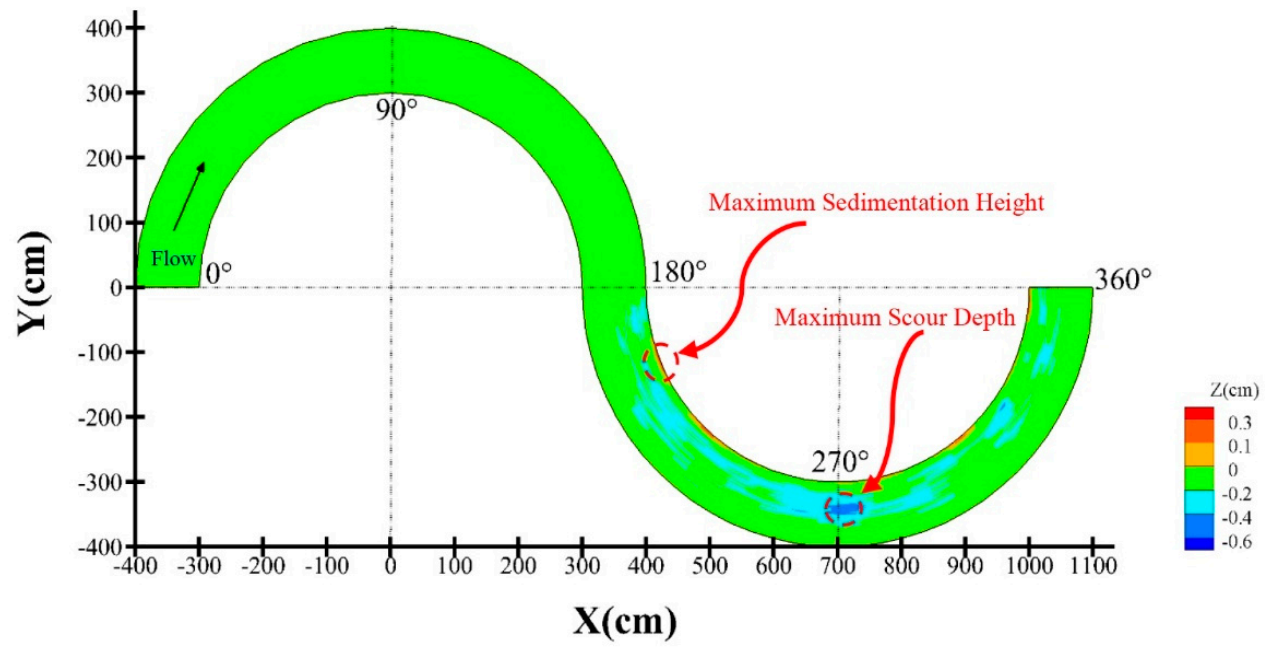

(b)

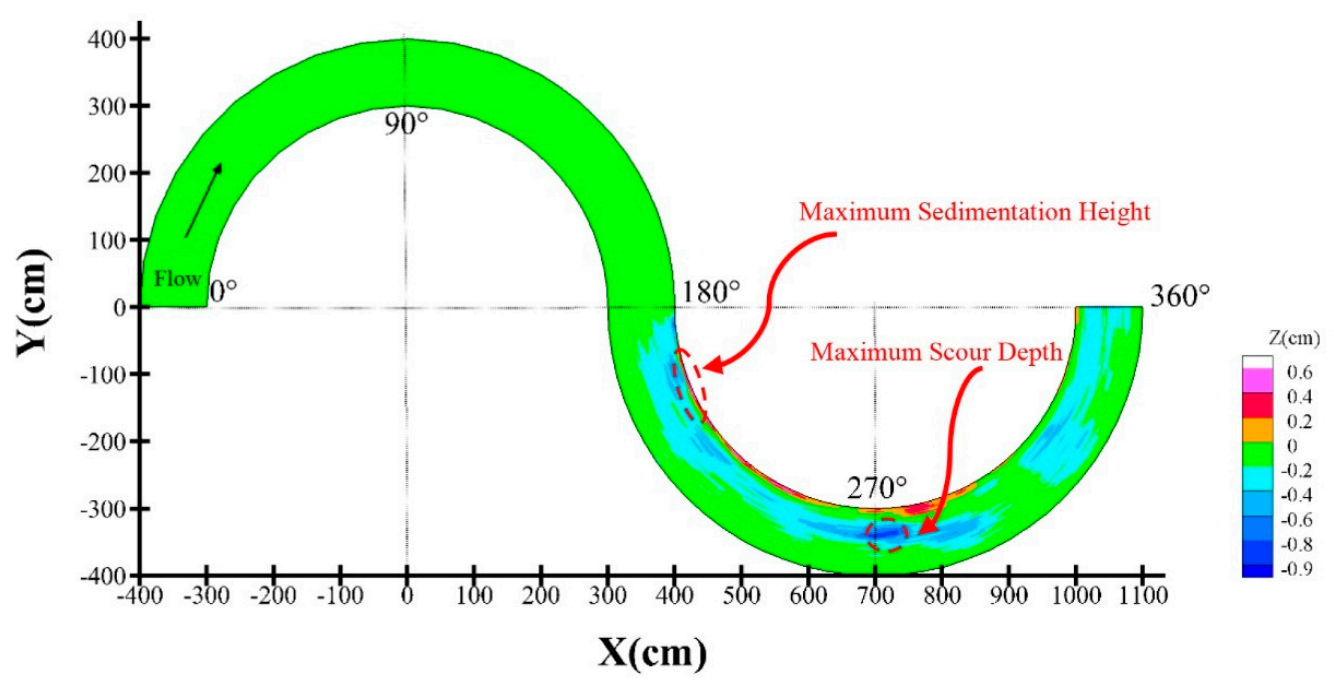

(c)

Figure 3. Cont. 


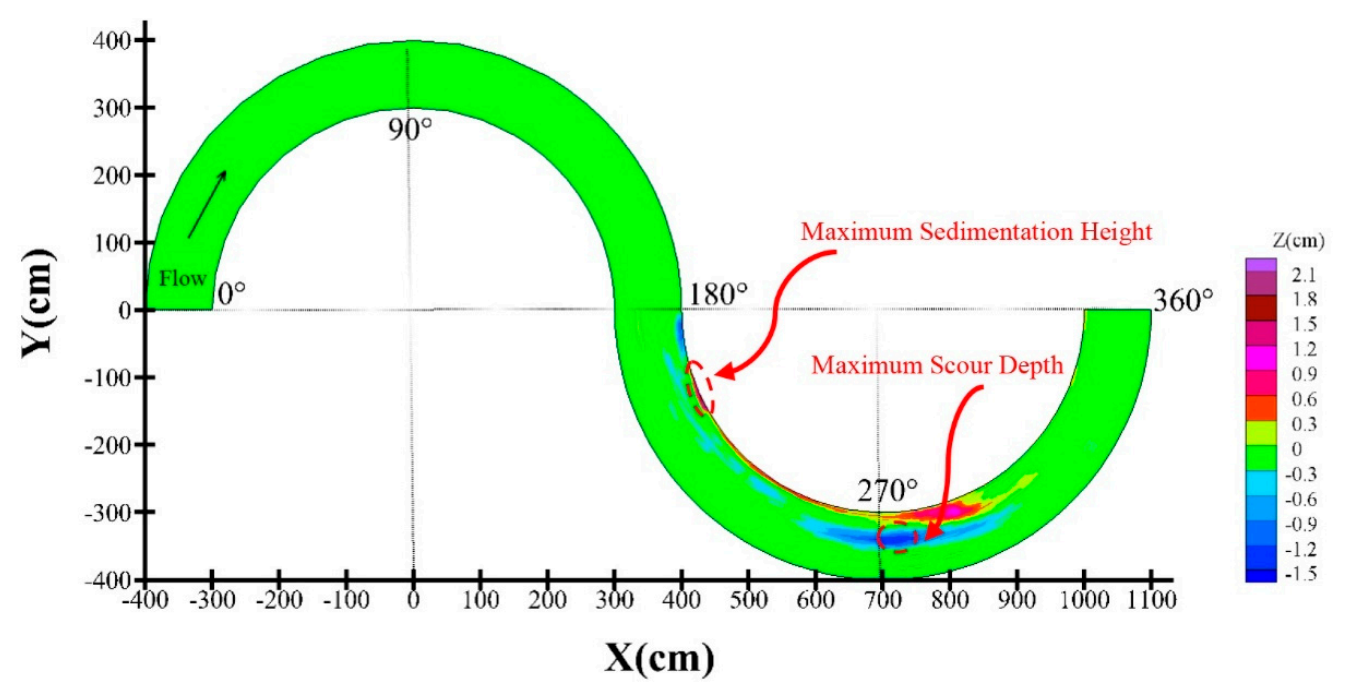

(d)

Figure 3. Bed topography variations for different U/Uc values: (a) 0.75 , (b) 0.8, (c) 0.84 , and (d) 0.86 .

Bed topography variations are shown in Figure 4 in tests with U/Uc values ranging from 0.89 to 0.98 . As shown in Figure $4 \mathrm{a}(\mathrm{U} / \mathrm{Uc}=0.89)$, the secondary flow strength in the first half of the upstream bend was not high enough to cause a change in bed topography. On the other hand, the variations occurred trivially in the second half of the bend from 170 to 180 degrees at the outer bank so that the maximum scour depth, $0.8 \mathrm{~cm}$, occurred at the 180-degree angle. This can be taken as the described incipient motion condition at the upstream bend in the meandering channel. In other words, when U/Uc was 0.89 at the upstream straight path, the first bend hosted the incipient motion condition. The upstream bend's effect on the downstream bend is mainly due to an increased secondary flow strength, which breeds variations in topography, clearly observable at the downstream bend. Hence, the maximum scour depth, equivalent to $16.2 \mathrm{~d}_{50}(3 \mathrm{~cm})$, occurred at the 275-degree angle. The maximum sedimentation height, equivalent to $25 \mathrm{~d}_{50}(4.6 \mathrm{~cm})$, was also realized at the 200-degree angle. Moreover, increasing U/Uc from 0.86 to 0.89 doubled the maximum scour depth and sedimentation height.

In Figure $4 b$, the bed topography remained unchanged at the first half of the upstream bend, but more changes were observed in the second half at the outer bank from 170 to 180 degrees. The flow and scour patterns hitherto described suggest a resemblance between the results of this study and those of other researchers $[13,27]$ in a small-scale laboratory model of a meandering channel. As shown in this figure, the maximum scour depth, equivalent to $18.4 \mathrm{~d}_{50}(3.4 \mathrm{~cm})$, occurred at the 180-degree angle. Furthermore, a $3.4 \%$ increase in $\mathrm{U} / \mathrm{Uc}$ also raised the maximum scour depth at the end of the outer bend at the upstream bend by approximately a factor of 4 . Additionally, the largest bed topography variations at the downstream bend occurred within the range of 200 to 300 degrees, where the maximum scour depth, equal to $32.4 \mathrm{~d}_{50}(6 \mathrm{~cm})$, developed at the 190-degree angle. In this case, the maximum sedimentation height, equal to $52 \mathrm{~d}_{50}(9.6 \mathrm{~cm})$, was observed at the 220-degree angle. On the other hand, an increase in U/Uc at the upstream straight path resulted in doubled values of the maximum scour depth and sedimentation height reported.

In Figure $4 \mathrm{c}(\mathrm{U} / \mathrm{Uc}=0.95)$, the entrance of the flow into the first bend led to insignificant variations in bed topography at the first half of the upstream bend, while it created scour at the second half of the bend from 170 to 180 degrees at the outer bank. The maximum scour depth, equal to $19 \mathrm{~d}_{50}(3.5 \mathrm{~cm})$, occurred at the 180-degree angle. Here, the maximum scour depth and sedimentation height, respectively, equaled to $39 \mathrm{~d}_{50}$ and $53 \mathrm{~d}_{50}$ (corresponding to $7.2 \mathrm{~cm}$ and $9.8 \mathrm{~cm}$ ) and occurred at 195 and 225 degrees. Considering the explanations provided in this figure, it can be concluded that increasing $U / U c$ has not increased the maximum scour depth at the upstream bend and the maximum sedimen- 
tation height at the downstream bend. On the other hand, the maximum scour depth at the downstream bend was developed by 1.2 times at a distance of 5 to 10 degrees from the beginning of the bend under the influence of the shift in the flow direction at the junction of the two bends.

Bed topography variations in a single 180-degree sharp bend for $\mathrm{R} / \mathrm{B}=2$ and $\mathrm{U} / \mathrm{UC}_{\mathrm{C}}=0.96$ in an experimental study by Vaghefi et al. [28] and a numerical study by Asadollahi et al. [29] were similar to the results observed in the downstream bend in this study, as shown in Figure $4 \mathrm{c}$.

The results of this comparison indicate that in either channel, whether with sharp or mild bends, sedimentation begins at the inner bends from approximately 30 degrees. In the present study, given the use of mild bends, trivial variations of sedimentation were observed at the upstream bend's inner wall. Still, the intensity of sedimentation was greater in a sharp bend. Moreover, an investigation of the scour pattern at the downstream meandering bend in comparison with the 180-degree sharp bend referred to the resemblance of the scour pattern in the middle of the bend in both cases; however, the maximum scour at the 180-degree sharp bend occurred from 40 to 80 degrees, whereas that in the meandering channel occurred at the 190-degree angle in the vicinity of the inner wall under the influence of the flows approaching from the upstream bend. These observations are also in line with Termini's investigations [27] in a meandering channel with consecutive bends on the maximum scour, which occurred at the second inner bend downstream. Moreover, Randle [1] also showed that the maximum shear stress occurred at the beginning of the next downstream bend.

Figure $4 \mathrm{~d}\left(\mathrm{U} / \mathrm{Uc}_{\mathrm{c}}=0.98\right)$ illustrates the bed materials' incipient motion at the upstream straight path; it may be observed that the flow velocity and strength have risen. Moreover, given the bed streamlines extended from the outer bank toward the inner bank, the first half's inner bank underwent sedimentation first. Still, the sedimentation variations in the first half were trivial since the bend was mild. Since the secondary flow in the second half of the upstream bend was directed toward the outer bank, as with the previous cases, the maximum scour occurred at the outer bank between 170 and 180 degrees. The maximum scour depth, equal to $65 \mathrm{~d}_{50}(12.1 \mathrm{~cm})$, was found at the 178 -degree angle. As with the previous cases, the maximum bed topography variations at the downstream bend occurred from 200 to 300 degrees. This region hosted the greatest secondary flow strength and the influence of the helical flow in the bend. Such a strong flow stems from the helical flow present inside the downstream bend itself, and its excessive increase is a consequence of the upstream bend geometry's affecting the downstream bend. The maximum scour depth and sedimentation height, separately equaled to $85 \mathrm{~d}_{50}$ and $60.5 \mathrm{~d}_{50}(15.8$ and $11.2 \mathrm{~cm})$ and occurred at 195 and 240 degrees, respectively. A comparison between Figures 3d and 4c indicates that for a change in U/Uc from 0.95 to 0.98 , the maximum scour depth at the upstream bend increased by 3.5 times. Additionally, at the downstream bend, the maximum scour depth and sedimentation height, respectively, increased by 2.2 and 1.1 times.

In general, a comparison made between different cases presented in Figure 4 suggests that a decline in the water level and an increase in velocity happened given the straight downstream path's effect and its effect on the meander (particularly on the second half of it). This has entailed further bed topography variations at the downstream bend, more specifically at the second half. Furthermore, the downstream bend functioned as an obstacle against the flow present at the upstream bend. This behavior resulted in fewer bed topography variations observed at the upstream bend than those at the downstream bend. A review of the general bed topography variations illustrated in Figures 3 and 4 explains why the maximum scour occurred at a distance of $5 \%$ from the outer bank between 178 and 180 degrees for every U/Uc value at the upstream bend. The maximum scour location at the downstream bend changed due to the influence of the upstream bend on the downstream bend and its velocity. As observed, from $U / U_{c}=0.8$ to $U / U_{c}=0.89$, the maximum scour occurred at distances of 30 to $40 \%$ of the channel width between 270 and 275-degree angles, whereas from $U / U_{c}=0.92$ to $U / U_{c}=0.98$, the maximum scour occurred 
at a distance of 5\% from the inner bank between 185- and 195-degree angles. Furthermore, since the flow in the first half of the downstream bend was directed toward the inner bank, the maximum sedimentation volume also occurred at a distance from 0 to $5 \%$ of channel width from the inner bank for all cases. Increasing U/Uc from 0.8 to 0.98 changed the location of the maximum sedimentation volume from 195- to 245-degree angles.

Figure 5 illustrates camera photos of bed topography variations in the laboratory for $\mathrm{U} / \mathrm{Uc}=0.98$. Figure $5 \mathrm{a}$ depicts the tail area of the first upstream bend and the second downstream bend entrance up to the 235-degree angle. As it can be observed here, the scouring occurred from the 165-degree angle at the tail area of the upstream bend to the junction between the two bends (area A1). It continued to the 200-degree angle at the downstream inner bend entrance in area A2 (similar to the trend described in Figure 4d). The scour oriented toward the middle of the bend from the 195-degree angle. The scour at the downstream inner bend continued to the 210-degree angle, after which sedimentation was observed (A3). There were also no variations observed in the vicinity of the downstream outer bend (A4).

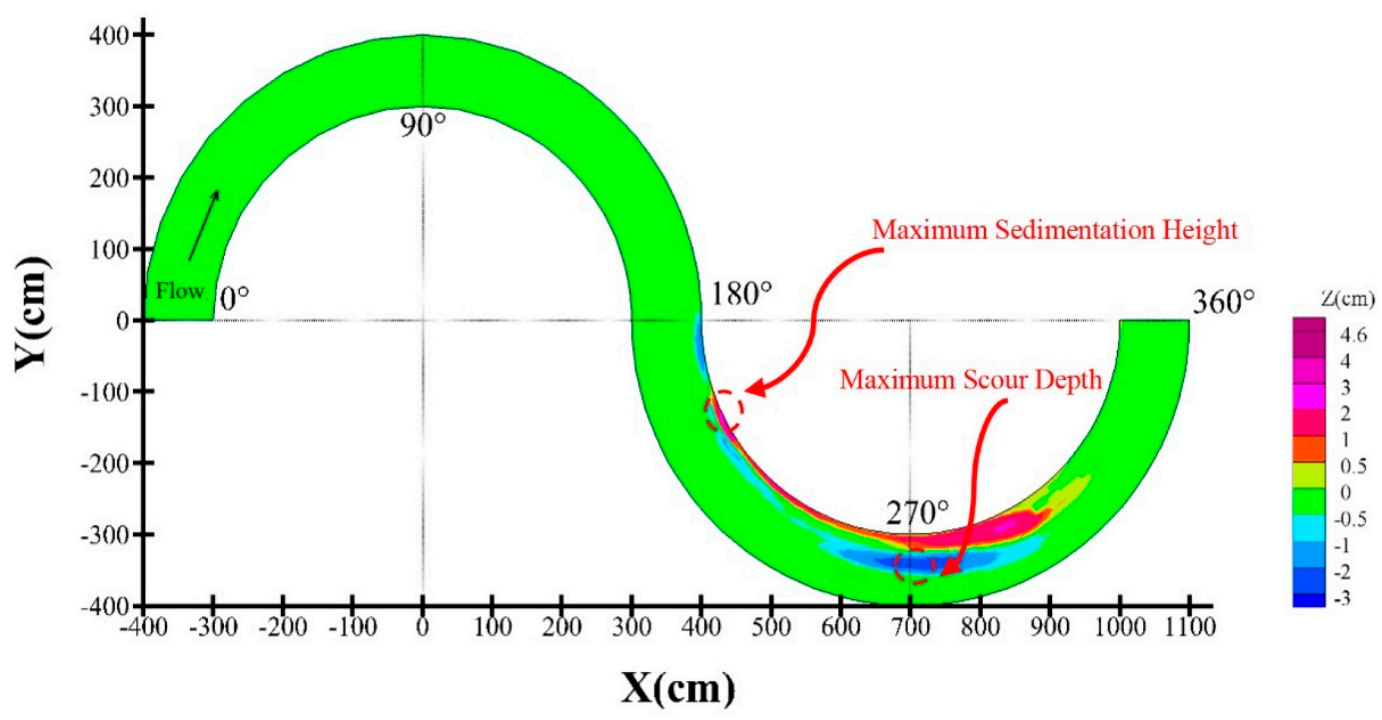

(a)

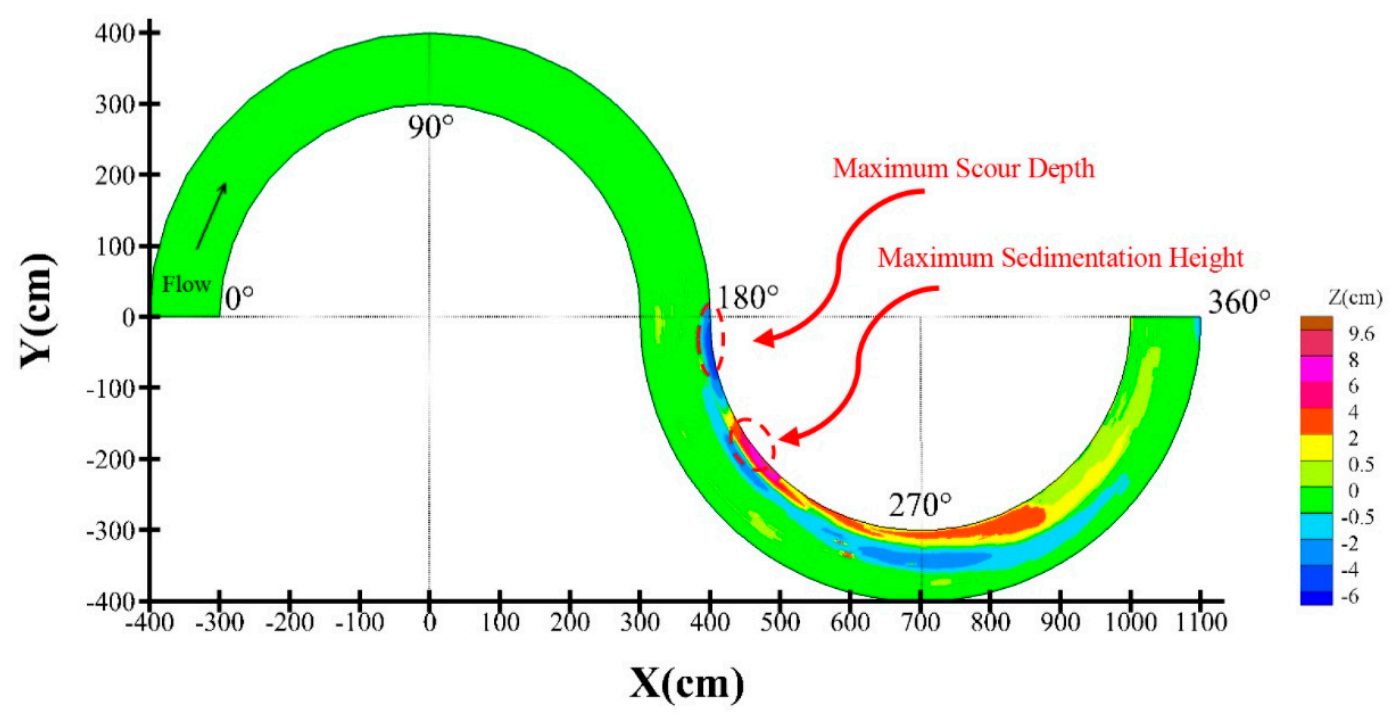

(b)

Figure 4. Cont. 


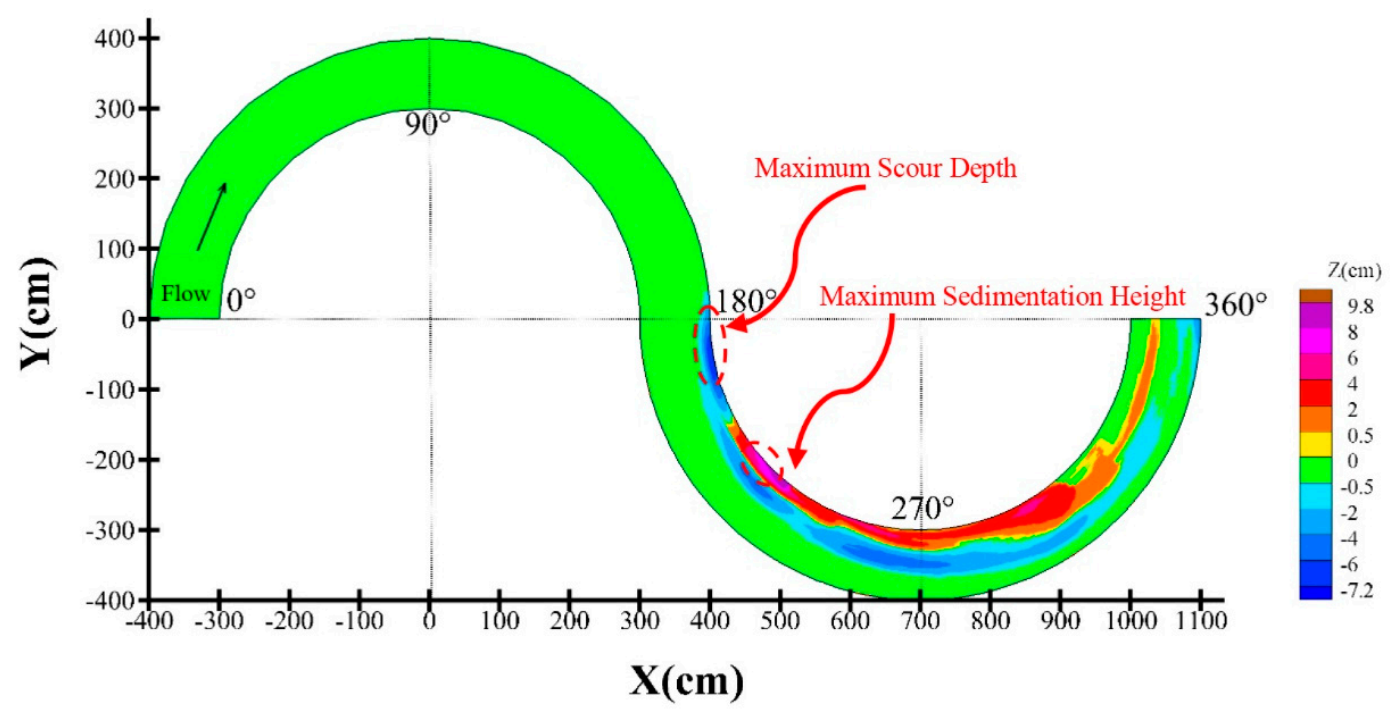

(c)

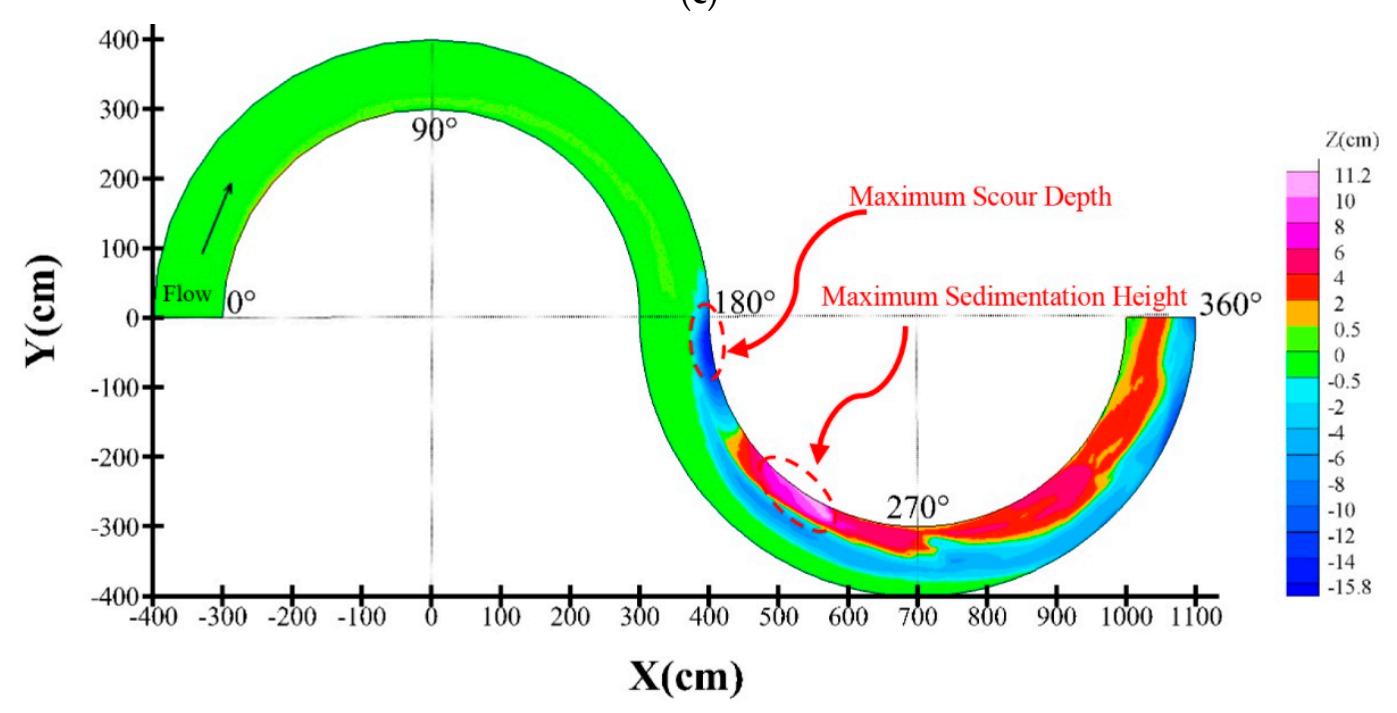

(d)

Figure 4. Bed topography variations for different U/Uc values: (a) 0.89, (b) 0.92, (c) 0.95, and (d) 0.98 .

In Figure 5b, bed topography variations in the first half of the downstream inner bend indicate sedimentation in area B1 from 217 to 280 degrees, while scour was observed at mid-channel (B2). Area B3, near the outer bend, still remained unchanged.

Figure 5 c illustrates topography variations from 250 to 310 degrees. Area $C 1$, near the downstream inner bank, underwent sedimentation, while area $\mathrm{C} 2$ in the middle of the bend was scoured. Sedimentation near the inner bend was oriented toward the mid-channel from the 255-degree angle. In area C3, there were no identifiable variations in topography to the 290-degree angle; however, the shift in the flow direction at the 300-degree angle toward the outer bend entails scouring in this area.

Figure $5 \mathrm{~d}$ depicts bed variations from 300- to 360-degree angles of the downstream bend. In area D1, near the inner bank, there were sedimentary stacks observed with an orientation toward the middle of the bend, and in area D2, scouring was found at the outer bend. As shown in these figures, the observations recorded about bed topography variations in the meandering channel in the laboratory are completely in line with the descriptions provided in Figure 4, particularly for $\mathrm{U} / \mathrm{Uc}=0.98$ in Figure 4d. 


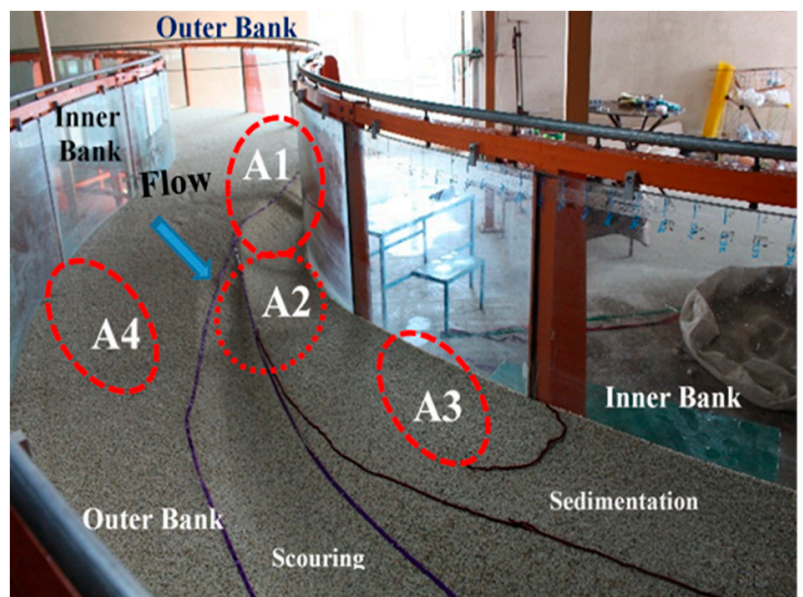

(a)

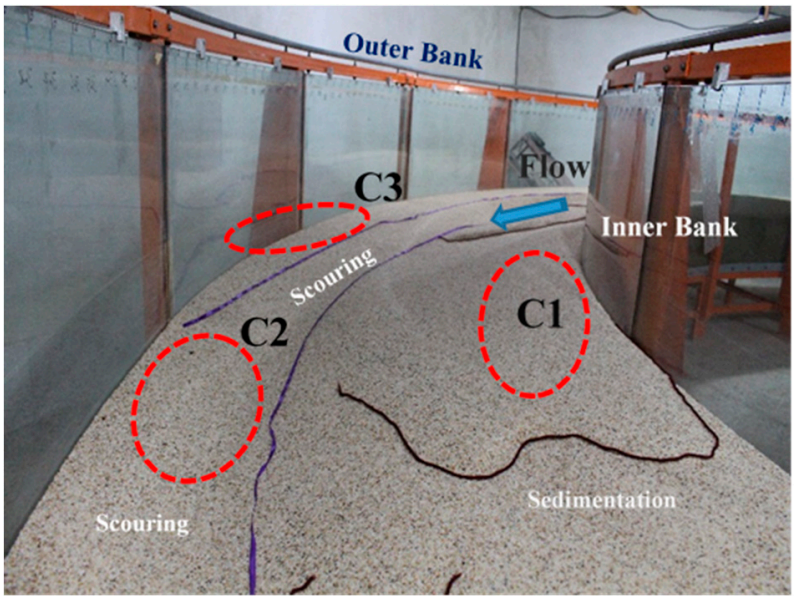

(c)

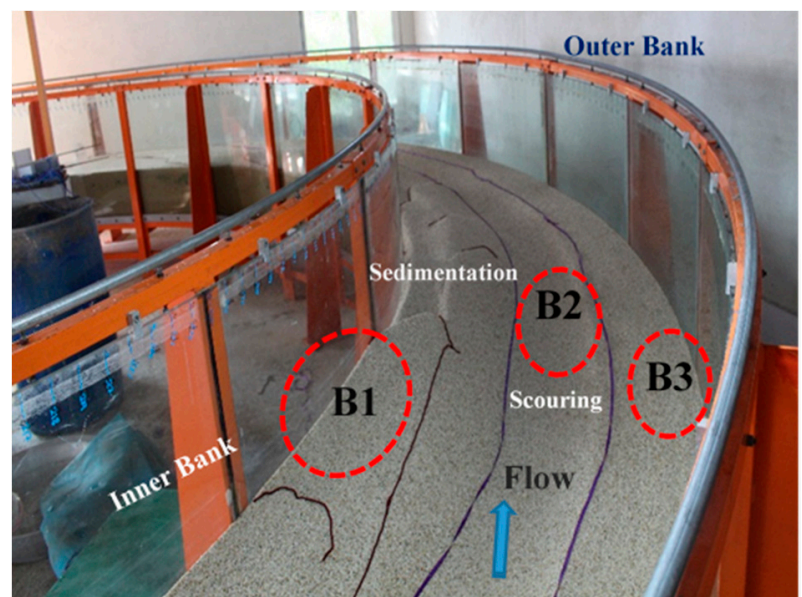

(b)

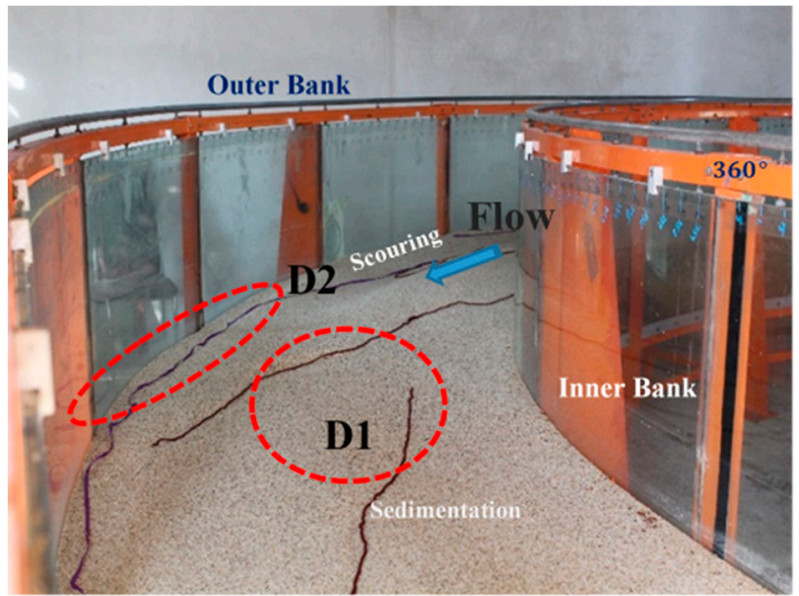

(d)

Figure 5. Instances of bed topography variations in the laboratory for U/Uc $=0.98$ between (a) 165 and 235, (b) 217 and 280, (c) 250 and 310, and (d) 300 and 360 degrees.

Table 2 presents the amount of increase in the maximum scour and sedimentation values and the increase in the volume of sediment output at upstream and downstream bends for different ratios of U/Uc. There are various methods for calculating the sediment output volume, among which hydrography datasets and bathymetry data may be mentioned. Moreover, the application of different software programs, such as HEC-RAS, GSTARS3, Mike21, and Tecplot 360 [30], is one of the prevalent methods of calculating sediment volume. In this study, Tecplot 360 was used for calculating the volume of sediment output. To this end, the collected data were inserted into the software, and after drawing bed topography, the volume of the sediments was calculated using the integration command.

With this table taken into consideration, with an increase in U/Uc value from 0.89 to $0.92,0.95$, and 0.98 , the volume of sediment output from the bend increased by 38,46 , and 75 times, respectively, at the upstream bend. As shown here, the greatest variations related to the increased volume of the sediment output in both upstream and downstream bends occurred in the last case, where $\mathrm{U} / \mathrm{Uc}_{\mathrm{c}}=0.98$ (which is the incipient motion of sediments on the upstream straight path). This can be attributed to the increase in the strength of eddies in this case. 
Table 2. Comparison between variations in the maximum scour and sedimentation values for different $U / U c$ values in the meandering channel.

\begin{tabular}{ccccc}
\hline Bend Location & U/Uc Variations & $\begin{array}{c}\text { Increase in the Maximum } \\
\text { Sedimentation Height }\end{array}$ & $\begin{array}{c}\text { An Increase in the } \\
\text { Maximum Scour Depth }\end{array}$ & $\begin{array}{c}\text { Increase in the Volume } \\
\text { of Sediment Output }\end{array}$ \\
\hline \multirow{5}{*}{ Upstream bend } & $0.75-0.80$ & - & - & - \\
& $0.80-0.84$ & - & - & - \\
& $0.84-0.86$ & - & - & - \\
& $0.86-0.89$ & - & 4.25 & 37.9 \\
& $0.89-0.92$ & - & 3.03 & 1.21 \\
& $0.92-0.95$ & - & - & 1.63 \\
Downstream bend & $0.95-0.98$ & - & 1.50 & 1.33 \\
& $0.75-0.80$ & - & 1.67 & 1.18 \\
& $0.8-0.84$ & 3.00 & 2.00 & 1.30 \\
& $0.84-0.86$ & 3.50 & 2.00 & 1.66 \\
& $0.86-0.89$ & 2.20 & 1.20 & 2.19 \\
\hline
\end{tabular}

\subsection{Lateral Bed Profiles Variations}

Figure 6 illustrates variations in different lateral bed profiles from the beginning to the end of the upstream bend at 45-, 90-, 135-, and 180-degree angles. A comparison between Figure $6 \mathrm{a}-\mathrm{c}$ indicates that variations at the upstream bend were highly insignificant. Scour hole formation was only observed at the outer bend area, as depicted in Figure $6 \mathrm{~d}$. Approaching the end of the bend, as shown in this figure, the flow was influenced by the downstream bend, and the bed topography variations decreased at mid-channel. An increase in $\mathrm{U} / \mathrm{Uc}$ from 0.75 to 0.86 entailed trivial changes in bed topography at the upstream bend. As the flow was oriented toward the outer bank in the second half of the bend, increasing $\mathrm{U} / \mathrm{Uc}$ from 0.89 to 0.98 caused scour-hole formation from 0 to $40 \%$ of the channel width from the outer bend. The variations from the mid-channel to the inner bank are insignificant.

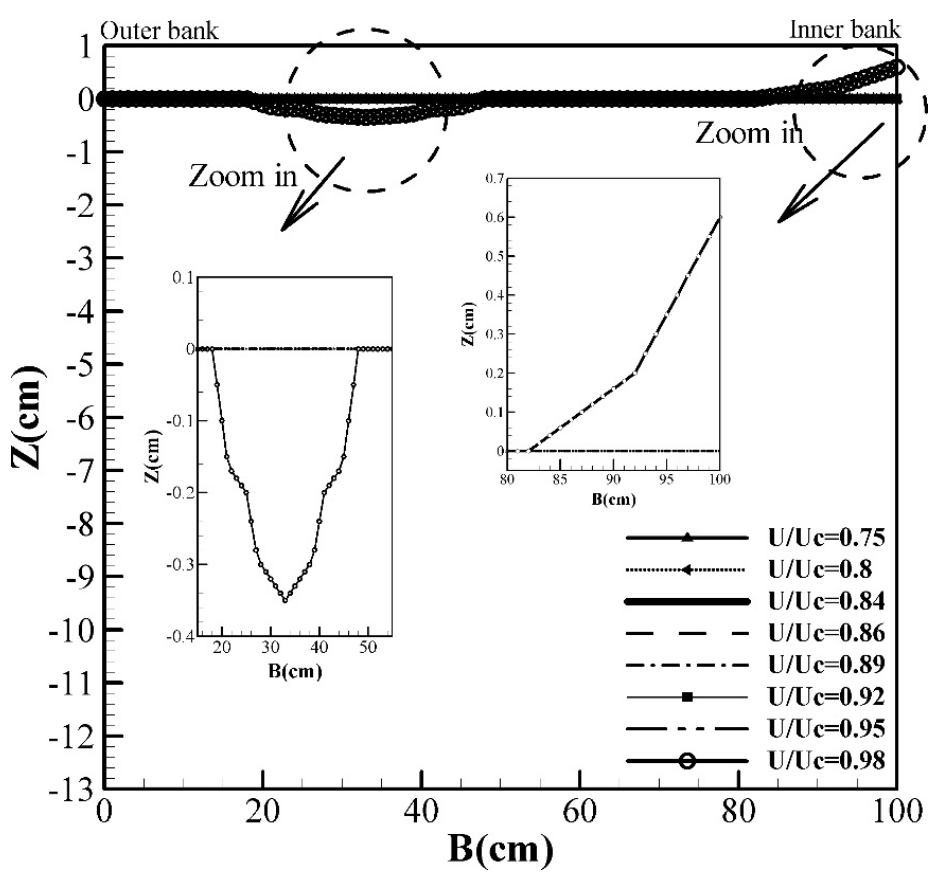

(a)

Figure 6. Cont. 


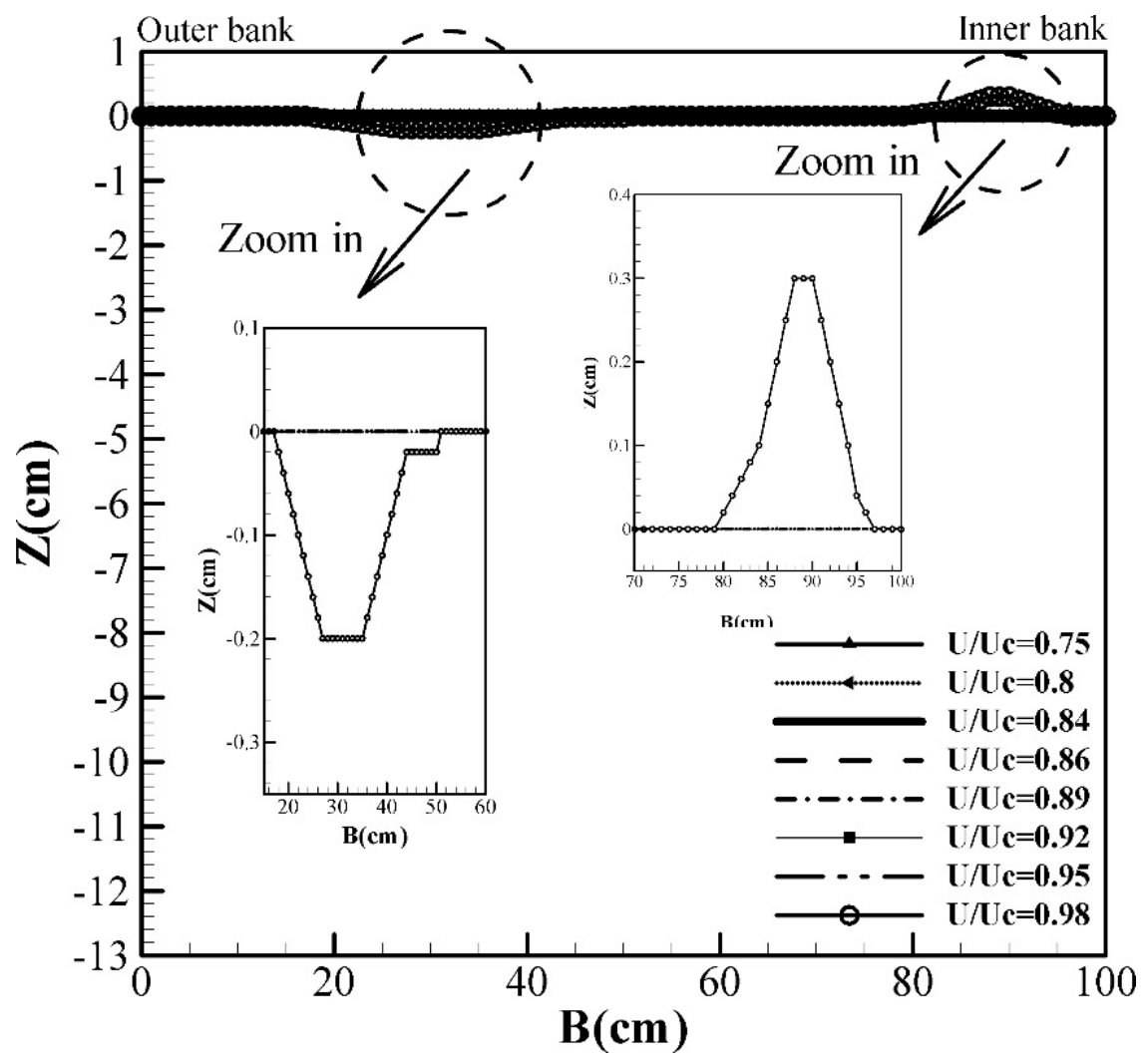

(b)

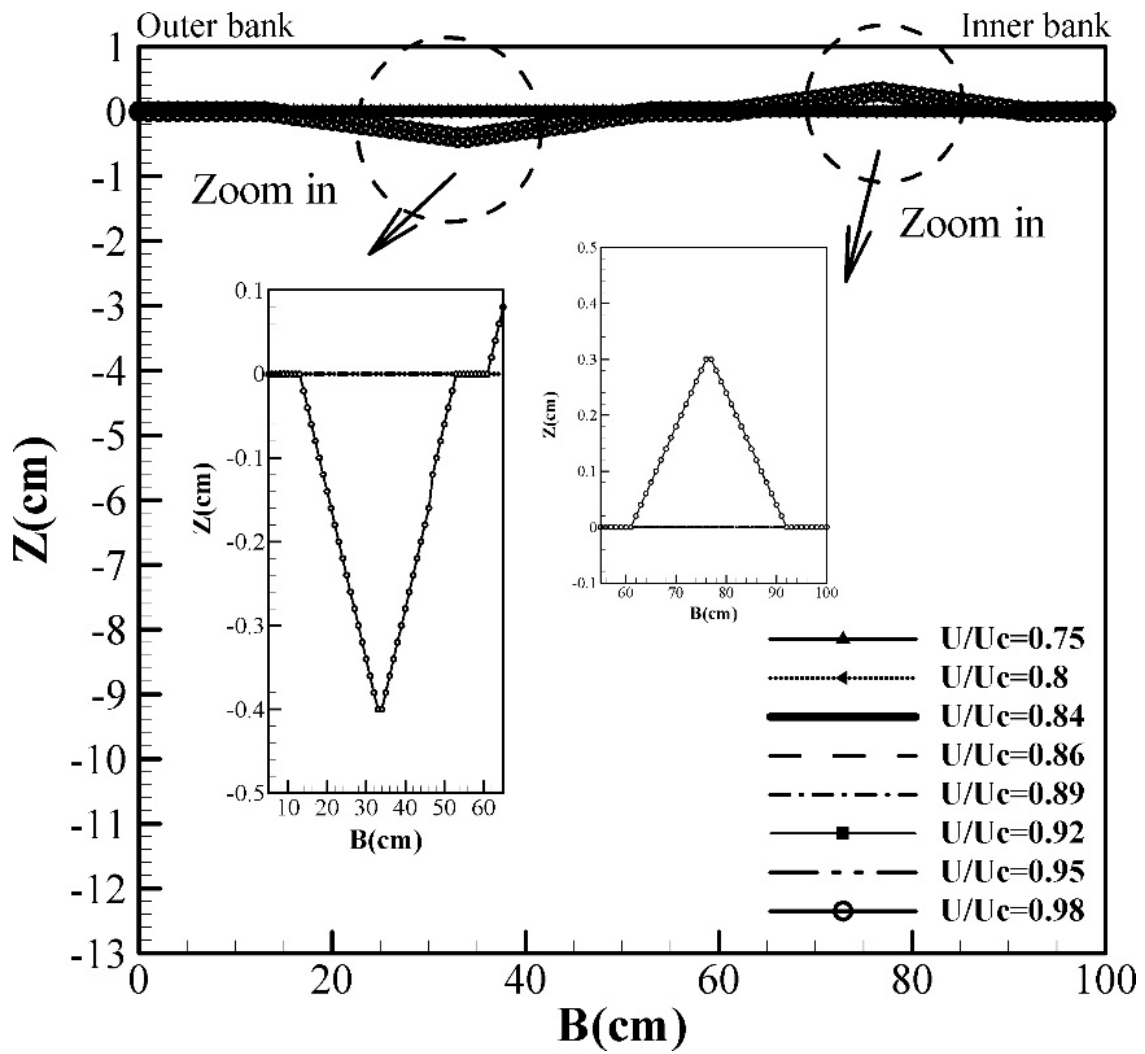

(c)

Figure 6. Cont. 


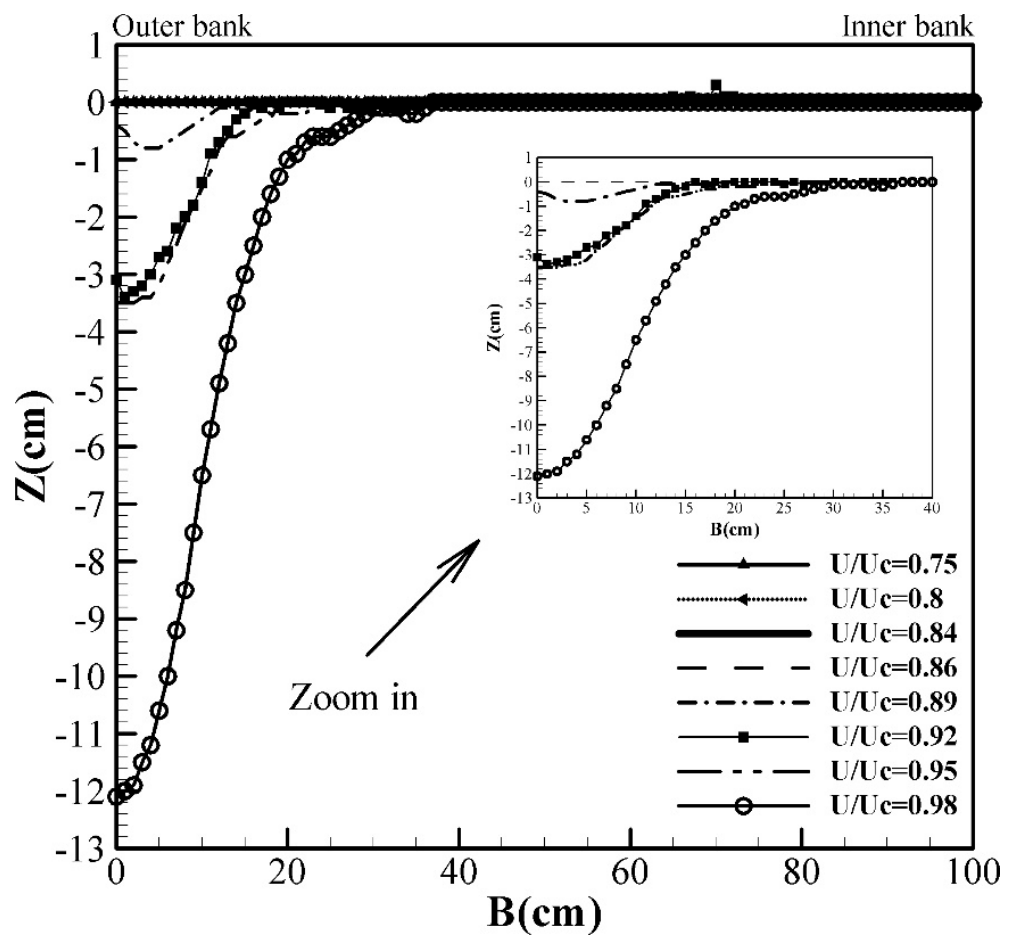

(d)

Figure 6. Instances of variations in the lateral bed profiles at (a) 45-, (b) 90-, (c) 135-, and (d) 180-degree angles of the upstream bend.

Instances of variations in lateral bed profiles from the beginning to the end of the downstream bend are shown in Figure 7 at 225-, 270-, 315-, and 360-degree angles. As shown in Figure 7a, given the flow direction toward the inner bank in the first half of the bend, sedimentation occurred at the inner bank. It continued to a distance of approximately $20 \%$ of the channel width from the inner bank. The secondary flows also caused the separation of sediments from the outer bank and mid-channel, whose result is scour-hole generation at a distance of 20 to $60 \%$ from the outer bank. There were no variations found in bed topography in the rest of the channel width. At this angle, increasing $\mathrm{U} / \mathrm{Uc}$ from 0.8 to $0.84,0.86,0.89,0.92$, and 0.98 , respectively, increased the maximum sedimentation height by $2.5,3,6,48,47$, and 41 times. With the same amount of increase in $\mathrm{U} / \mathrm{Uc}$, the maximum scour depth also increased by 1.5, 2, 3, 8, 16, and 22 .

In Figure $7 \mathrm{~b}$, given the mid-channel flow orientation at the 270-degree angle, the sediments were gradually carried away from the inner bank. It can be observed that the maximum sedimentation occurred within the range of 10 to $20 \%$ of the channel width from the inner bank. On account of this figure, sedimentation continued to $30 \%$ of the channel width from the inner bank, and scour-hole generation was observed at the distance of 35 to $75 \%$ from the inner bank. By increasing $\mathrm{U} / \mathrm{Uc}_{\mathrm{c}}$ from 0.8 to 0.84 and 0.86 , the maximum sedimentation height remained unchanged at this angle, but increasing it to $0.89,0.92$, 0.95 , and 0.98 increased the maximum sedimentation height by factors of $4,7,7.5$, and 13, respectively. Moreover, the maximum scour depth, respectively, increased by 1.5, 2, 3, 4, 5, and 4.5 times because of increasing $\mathrm{U} / \mathrm{Uc}$.

In Figure 7c, when the flow entered the second half of the downstream bend at the 315-degree angle and the helical flows decline, bed topography depended on the sediments carried downstream from the upstream bend. In the second half of the bend, the sediments were gradually carried away from the inner bank and mid-channel. With the flow orienting toward mid-channel and then toward the outer bank, scour-hole generation occurred from mid-channel to the outer bend. 
A comparison between Figure 7a-c indicates that at the 225-degree cross section, the maximum sedimentation occurred at the inner bank, but at 270 and 315-degree cross sections, with the shift in the flow orientation toward mid-channel and the outer bank, the maximum sedimentation height was observed from 10 to $20 \%$ of the channel width from the inner bank. The maximum sedimentation height remained unchanged at the 315 -degree cross section with an increase in $\mathrm{U} / \mathrm{Uc}$ value from 0.8 to 0.84 and 0.86 , as was also the case with the 225-degree section. However, with an increase in U/Uc from 0.8 to $0.89,0.92,0.95$, and 0.98 , the maximum sedimentation height increased by $2,4,8$, and 26 times. The maximum scour depth analysis indicates that increasing $\mathrm{U} / \mathrm{Uc}_{\mathrm{c}}$ from 0.8 to $0.84,0.86,0.89$, and 0.92 did not change the value, but increasing it from 0.8 to 0.95 and 0.98 increased the maximum scour depth by factors of 3 and 15 .

In Figure $7 d$, in experiments with $U / U c=0.95$ and 0.98 , the sediments washed by the flow recede from the inner bank were deviated toward mid-channel under the influence of the straight downstream path and deposited at the end of the bend, resulting in the accumulation of sedimentary stacks within the range of the inner bend to mid-channel. There was insignificant sedimentation observed in the vicinity of the inner bank to midchannel in other tests. In every test, bed topography variations at mid-channel have decreased closer and closer to the bend's tail area under the downstream straight path's effect on the flow. With the flow deviated toward the outer bank, the scour hole occurred within the mid-channel range to the outer bend. As shown in this figure, increasing U/Uc from 0.8 to $0.84,0.86$, and 0.89 did not change the maximum scour and sedimentation. Increasing $\mathrm{U} / \mathrm{Uc}$ from 0.8 to $0.92,0.95$, and 0.98 increased the maximum sedimentation height by $2,2.5$, and 20 times, while the maximum scour depth increased by, respectively, 5 , 14 , and 33 times.

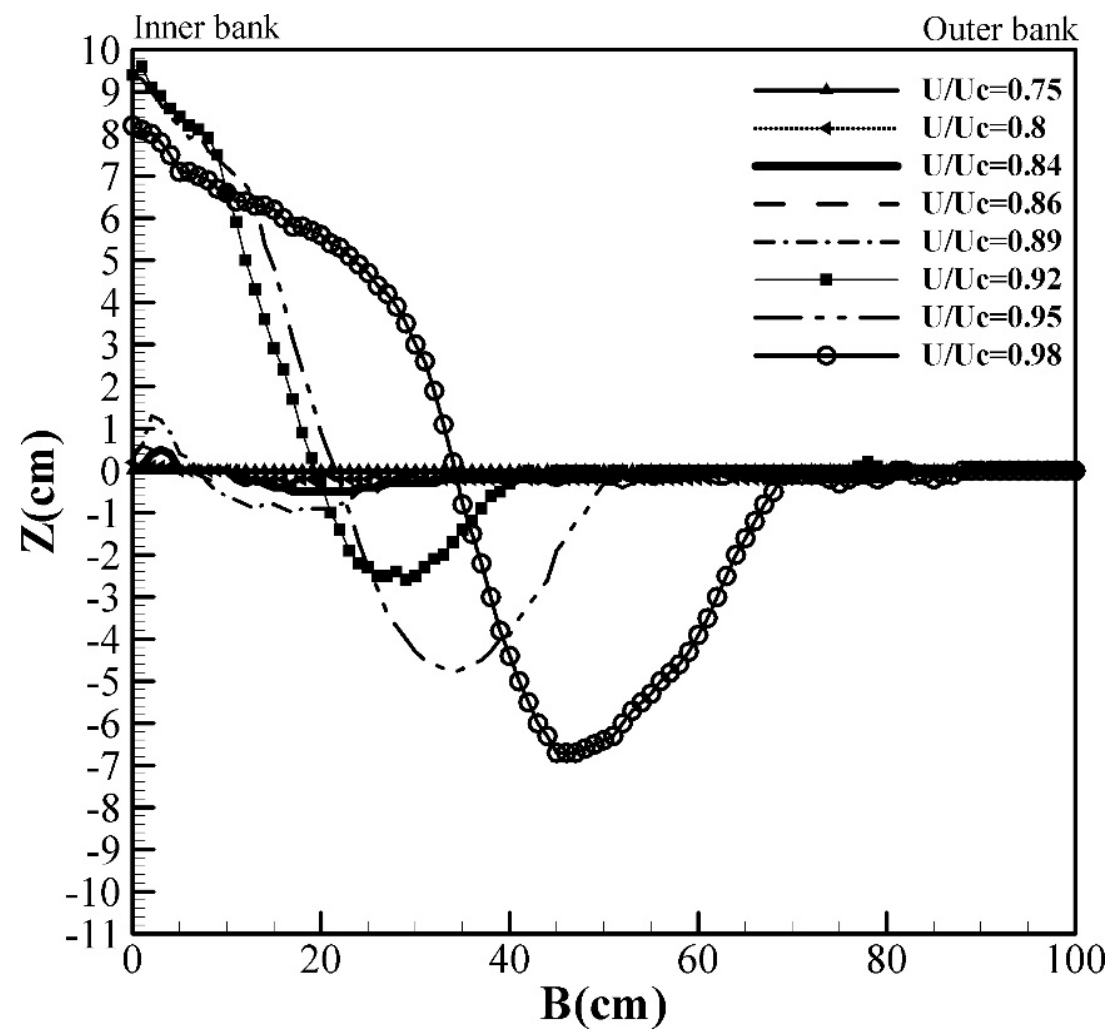

(a)

Figure 7. Cont. 


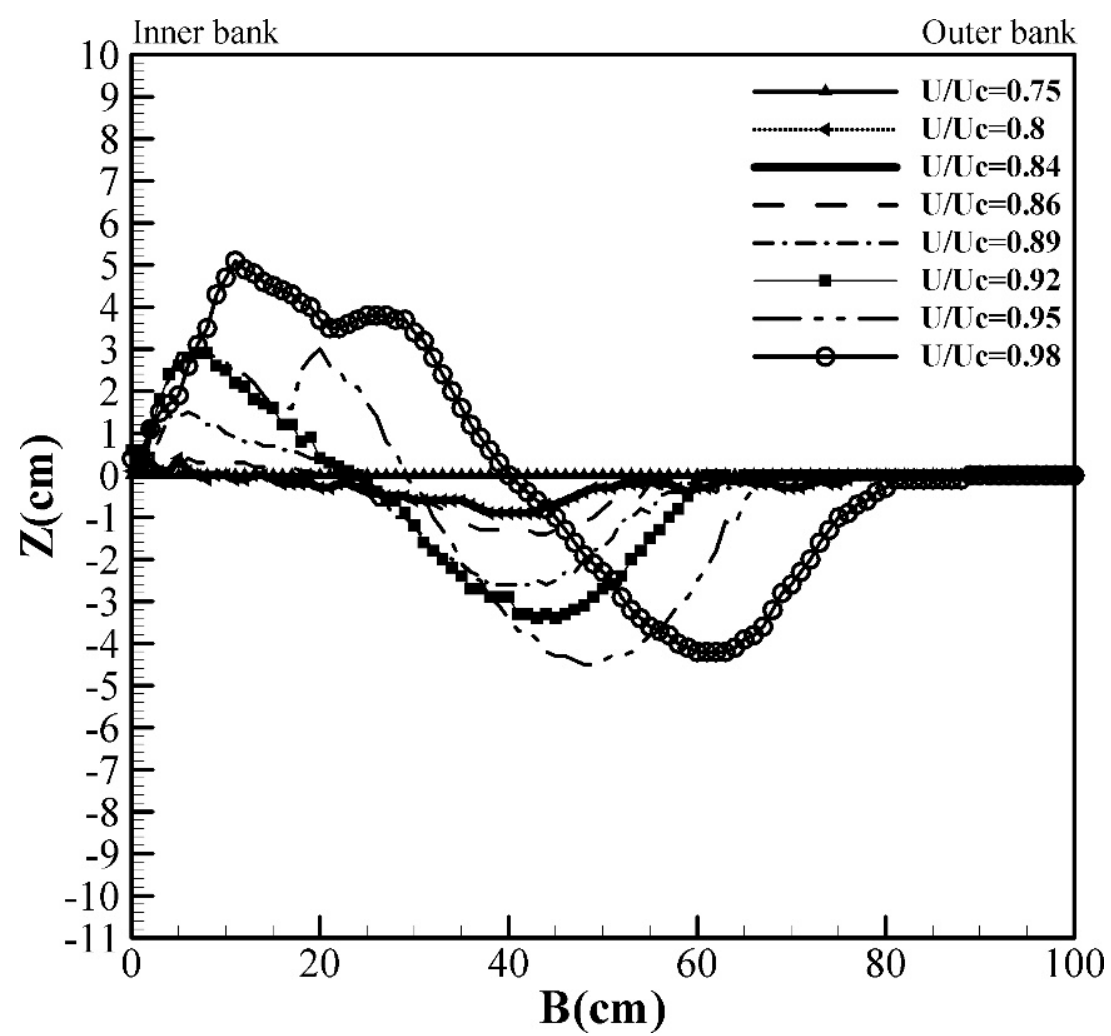

(b)

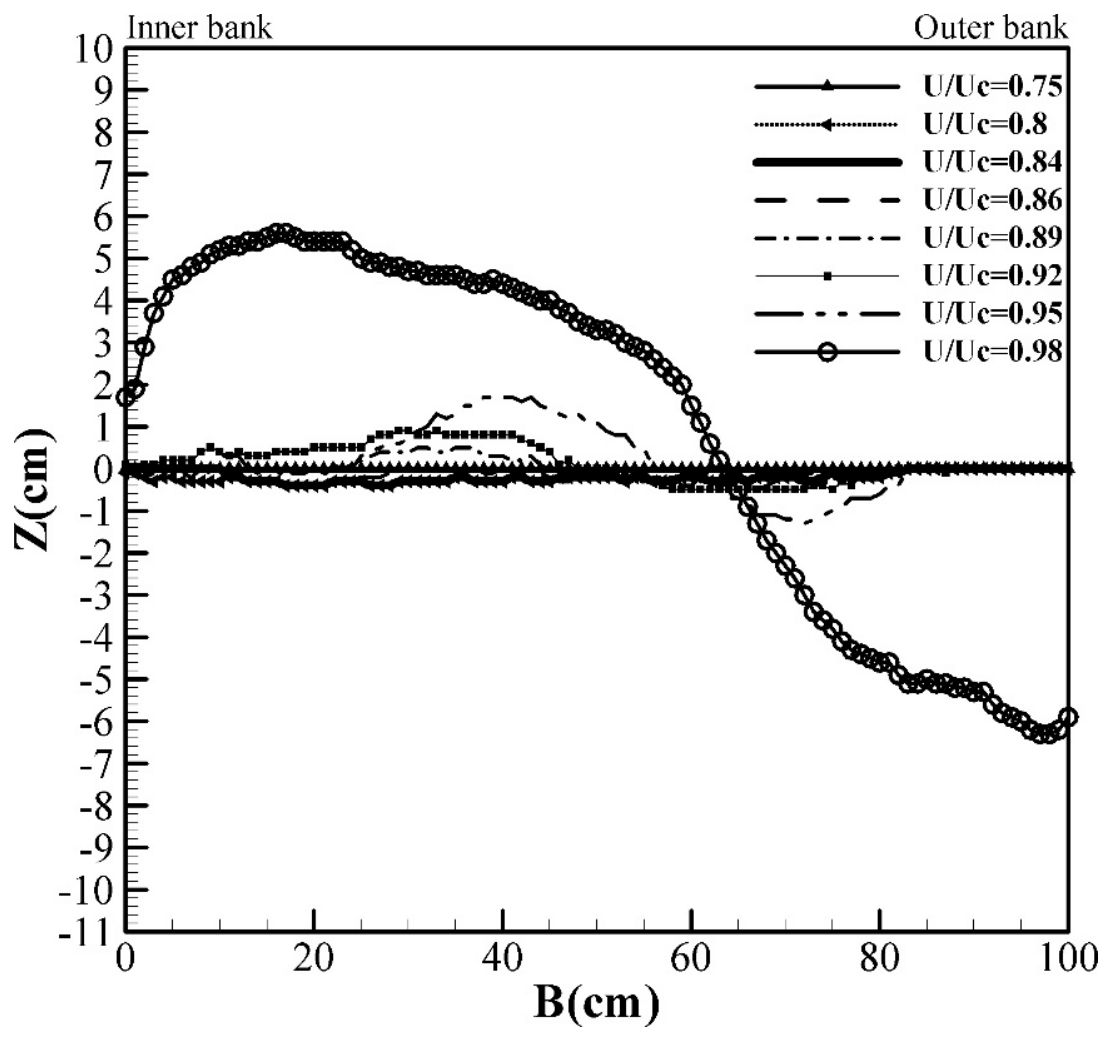

(c)

Figure 7. Cont. 


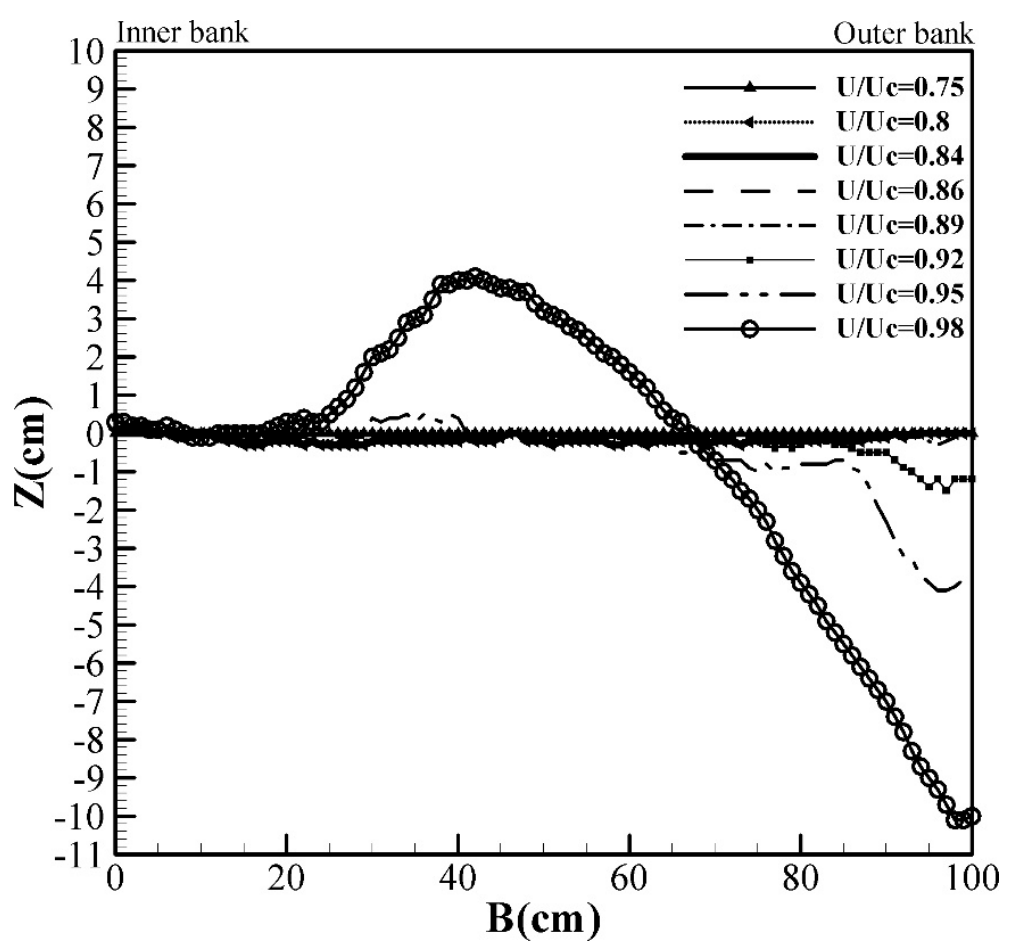

(d)

Figure 7. Instances of variations in the lateral bed profiles at (a) 225-, (b) 270-, (c) 315-, and (d) 360-degree angles of the downstream bend.

\subsection{Longitudinal Bed Profiles Variations}

Figure 8 illustrates instances of different longitudinal bed profiles from the beginning to the tail area of the channel at distances of 10,50 , and $90 \%$ of the channel width from the inner bank for different cases. According to this figure, most bed topography variations occurred from the tail area of the upstream bend to the end of the downstream bend. As shown in Figure 8a, bed topography had trivial variations at the upstream bend's outer bank. As the flow was oriented toward the outer bank in the second half of the upstream bend, the maximum scour hole was created within the range of 180 to 200 degrees. In this figure, sedimentation occurred from a range of $10 \%$ of the channel width from the inner bank at the 220-degree angle to the end of the downstream bend. It was intensified in the first half of the bend, where the maximum value occurred within the range of 240 to 260 degrees. These sedimentary stacks were carried downstream gradually away from the inner bank and toward mid-channel.

Figure $8 \mathrm{~b}$ illustrates how insignificant bed topography variations are from midchannel to the area short of the downstream bend. The flow was oriented toward the inner bank at the beginning of the downstream bend. The sediments washed out of the scour hole created in that area joined the sediments deposited from the upstream sections and headed downstream. With the bend geometry taken into consideration, the flow orientation gradually shifted away from the inner bank and directed toward the mid-channel and then the outer bank in the second half of the bend. Shifted toward the mid-channel in the second half of the bend, the flow shed over the sedimentary stacks, creating a scour hole at mid-channel within the range of 220 to 300 degrees. The sediments washed out of the scour hole joined the sediments deposited from upstream, and they were observed headed downstream. In time, these stacks and holes moved toward the outer bank and then through the downstream straight path, leading to the discharge of sediments from the bend.

As shown in Figure 8c, the scour was intensified at the outer bank and the second half of the bend, and its maximum occurred within the range of 300 to 360 degrees. The 
whole trend described in Figure 7 is also visible in Figure 3 (bed topography variations) and Figure 5 (variations in the lateral profile) within the same ranges as those in this case.

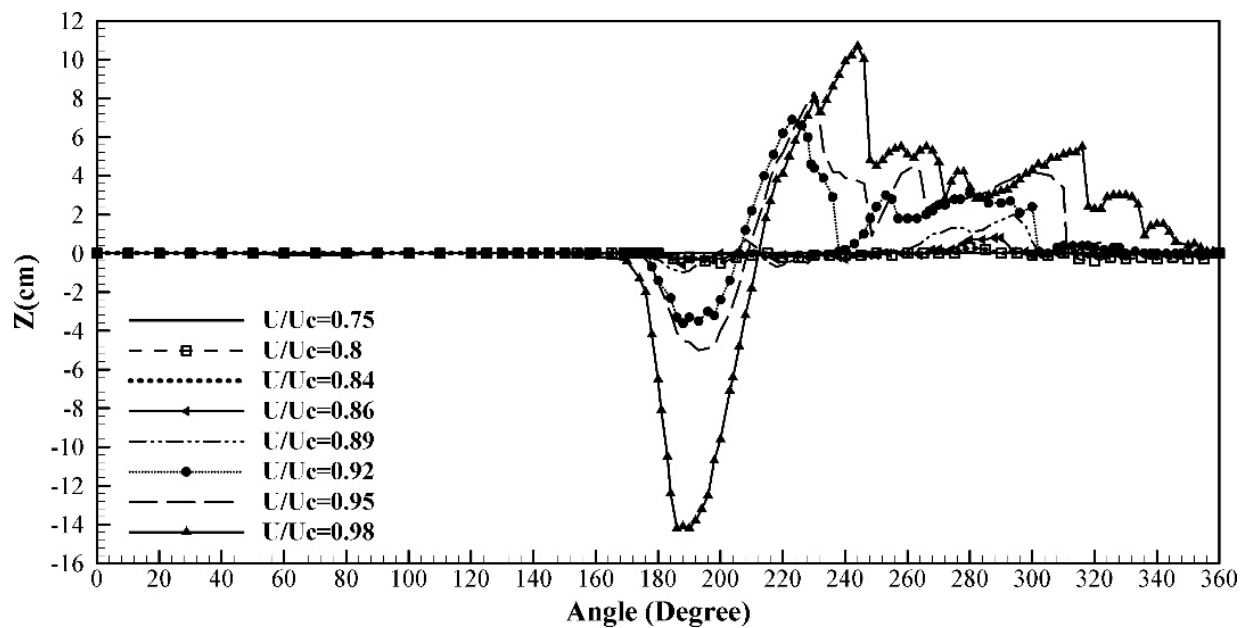

(a)

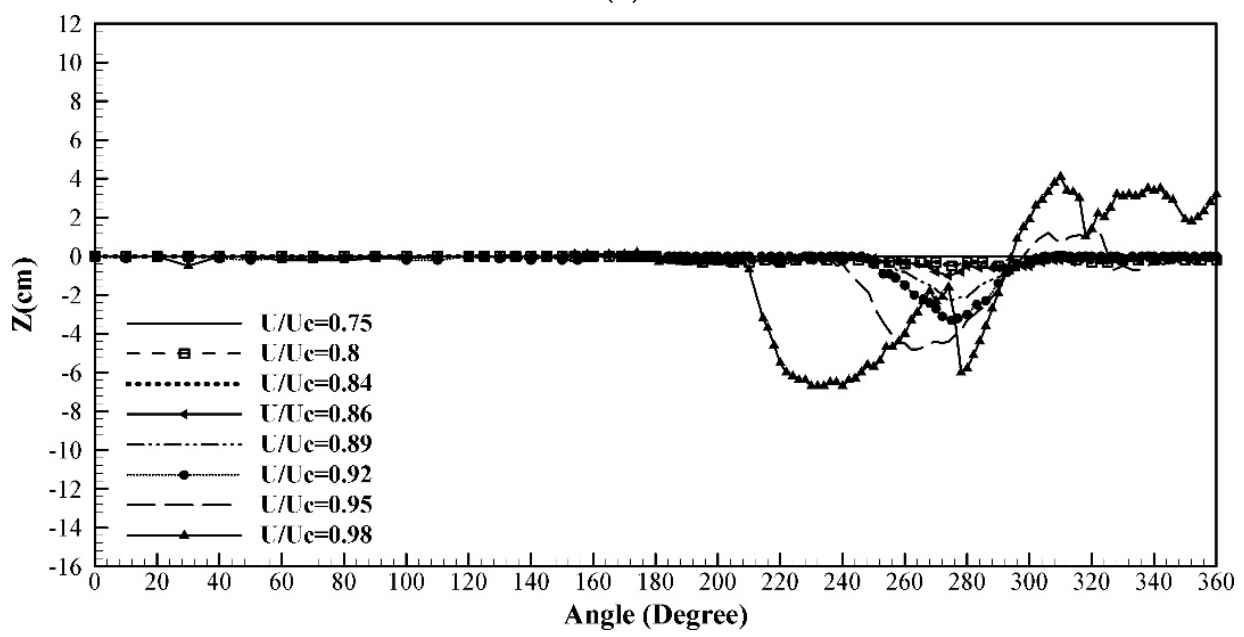

(b)

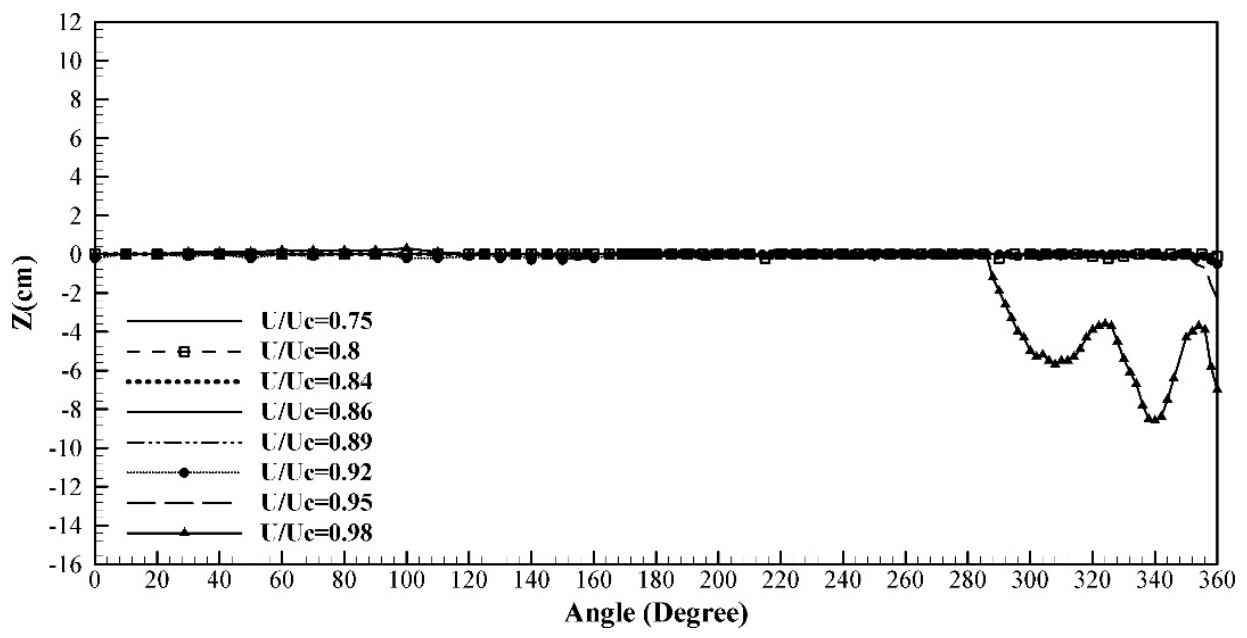

(c)

Figure 8. Instances of variations in the longitudinal bed profile at distances of (a) $10 \%$ of the channel width from the first outer bend and the second inner bend, (b) 50\% of the channel width, and (c) $90 \%$ of the channel width from the first inner bend and the second outer bend. 
An overall review of the results of bed topography variations along the meandering channel indicates that increasing $\mathrm{U} / \mathrm{Uc}$ from 0.89 to $0.92,0.95$, and 0.98 increased the maximum scour depth at the upstream bend by factors of $4.3,4.4$, and 15 , respectively. Increasing $\mathrm{U} / \mathrm{Uc}$ from 0.8 to $0.84,0.86,0.89,0.92,0.95$, and 0.98 at the downstream bend increased the maximum scour depth by, respectively, 1.5, 2.5, 5, 10, 12, and 26 times. Moreover, the maximum sedimentation also increased by factors of 3, 10, 23, 48, 49, and 56 due to the increase in this ratio.

\subsection{Qualitative Flow Pattern}

Figure 9 illustrates instances of the flow's qualitative behavior at the upstream and downstream bends in the meandering channel using colored ribbons (a purple ribbon at the layer near the water surface and a yellow ribbon at the layer near the bed). Figures $8 \mathrm{~b}$ and $9 \mathrm{a}$, respectively, depict sections from the first and the second halves of the upstream bend. Flow orientations toward the inner bend at the layers near the bed and toward the outer bend at the upper layers are evident in these figures. Figure $9 \mathrm{c}$ illustrates the beginning of the downstream bend. As shown in this figure, since the inner and outer bends swapped positions, compared to the upstream bend at the downstream bend inlet, the streamlines were again oriented toward the outer bank at the water surface. Figure $9 \mathrm{~d}$ depicts the flow at the end of the downstream bend. According to this figure, from approximately the 190-degree angle, the upper layers' flow was oriented from the outer bend toward the mid-channel. After the 300-degree angle, it was mostly influenced by the straight downstream path. This flow variations trend is in line with the descriptions provided in Figure 4 with respect to bed topography variations.

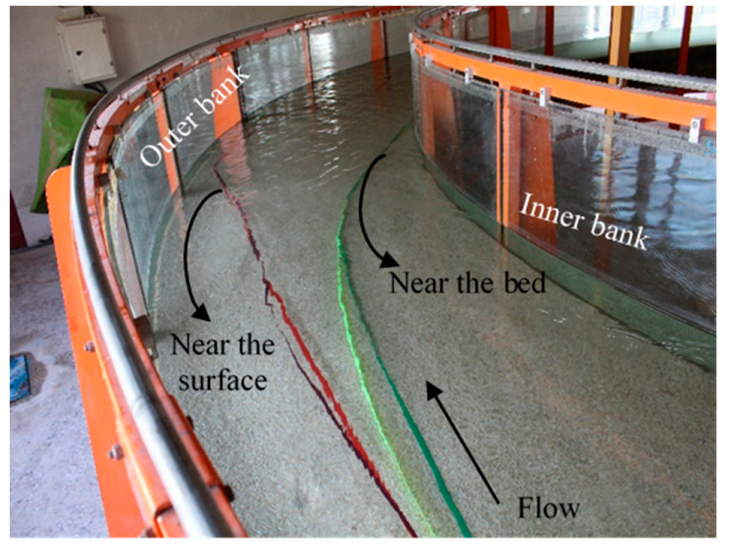

(a)

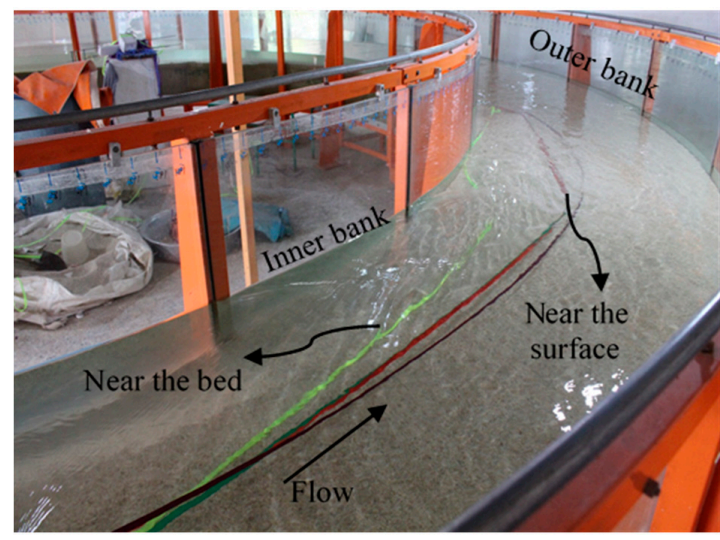

(c)

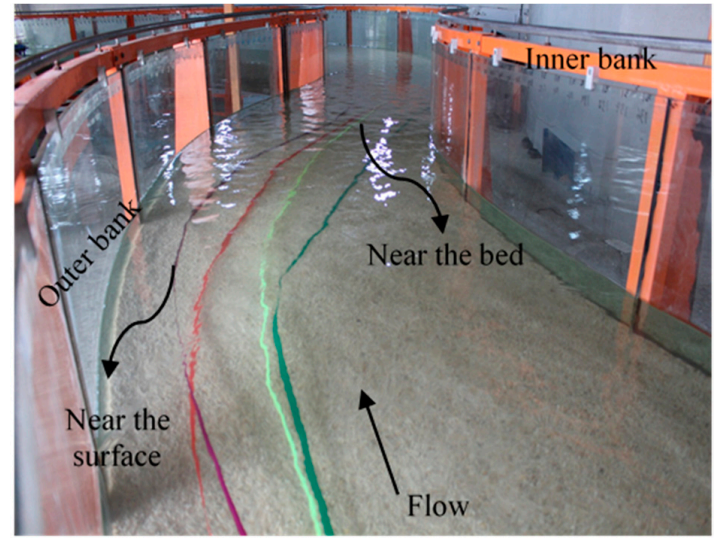

(b)

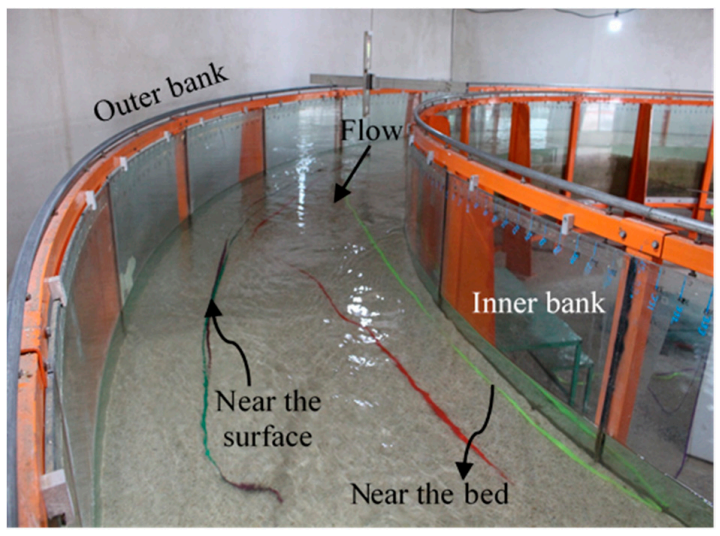

(d)

Figure 9. Instances of the qualitative flow behavior at the upstream and downstream bends of the meandering channel for $\mathrm{U} / \mathrm{Uc}=0.98$ at (a) the upstream bend inlet, (b) the upstream bend outlet, (c) the downstream bend inlet, and (d) the downstream bend outlet. 
Moreover, 3D views of the streamlines at the layers near the bed and those near the water surface along the meandering channel, and the helical flows [31] created along the path are schematically shown in Figure 10. As shown in this figure, the flow orientation near the water surface shifted toward the outer bend, and that at the layer near the bed shifted toward the inner bend. Additionally, the presence of helical flows in the bend created scour in the vicinity of the outer bend and sedimentation near the inner bend. These bed topography variations, which are affected by the presence of helical flows at the downstream bend for $\mathrm{U} / \mathrm{Uc}_{\mathrm{c}}=0.98$, are described in Figure $4 \mathrm{~d}$. Analysis of the qualitative flow pattern in Figure 9, the schematic illustration of the flow pattern in Figure 10, and the scour and sedimentation patterns in Figure 4 refer to the correspondence between the scour changes imposed on the meandering channel bends and the flow pattern. Moreover, the drawn vector in the figure also matches the streamlines presented by Vaghefi et al. [32] and Akbari and Vaghefi [33] at the layers near the bed (toward the inner bend) and the layer near the water surface (toward the outer bend) in a 180-degree sharp bend with $\mathrm{R} / \mathrm{B}=2$. In addition, flow pattern variations and their relationship with the real bed scouring taken place in the laboratory for $\mathrm{U} / \mathrm{Uc}_{\mathrm{c}}=0.98$ are well illustrated in Figure 5.

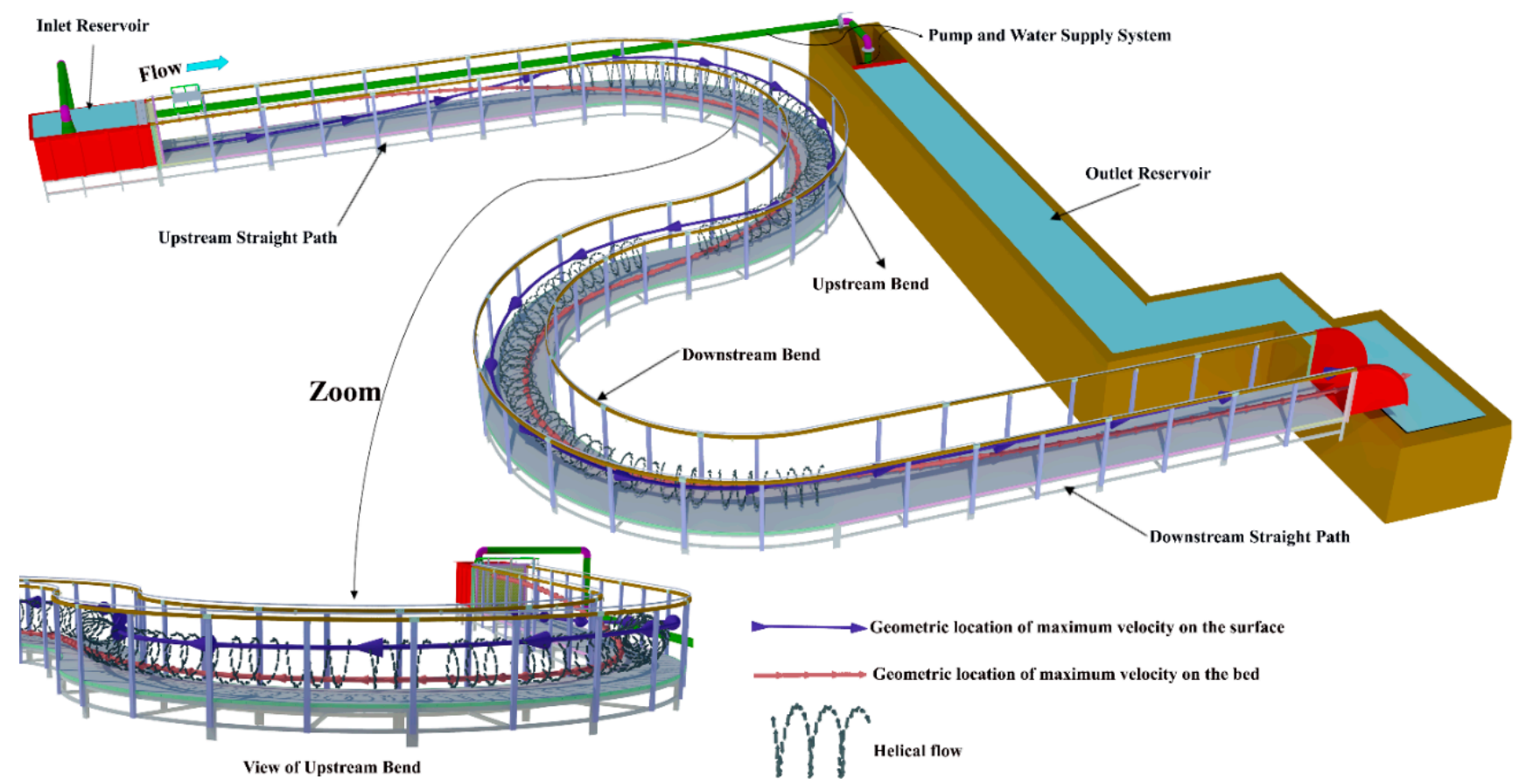

Figure 10. A schematic illustration of the 3D flow pattern at the layers near the bed and the water surface of the meandering channel.

\section{Conclusions}

This paper presented the experiments conducted for different mean velocity-to-critical velocity ratios $(\mathrm{U} / \mathrm{Uc})$ at the straight upstream path to determine the incipient motion conditions in a meandering channel with two consecutive 180-degree mild bends. This study's dimensionless results can be compared with the results of other experimental, numerical, or field studies that have a similar channel curvature, width-depth ratio, Froude number, and Reynolds. The measured parameters in this study (e.g., the maximum sedimentation and scouring locations, the bed topography variations, the channel bend's behavior, and the qualitative velocity pattern) are expected to be similar to those in other laboratory or natural channels under similar conditions. The following is a summary of the results obtained from this study:

- Bed topography variations at the upstream bend suggest the downstream bend's effectiveness in altering the incipient motion conditions along this bend. In addition to the downstream straight path's role in altering the incipient motion conditions, the 
upstream bend's geometry also affected bed topography variations at the downstream bend. These are in correspondence to the hypotheses presented in this study;

- $\quad$ For $\mathrm{U} / \mathrm{Uc}=0.89$ to 0.98 in both bends, bed topography changed under the bend geometry's influence. The reduction of water level at the upstream bend resulted in an increase in the flow velocity compared to that at the upstream straight path. The downstream bend also showed more bed topography variations than the upstream bend given its greater water level reduction than the first bend. For $\mathrm{U} / \mathrm{Uc}=0.89$ to 0.95 at the first bend, however, no sedimentation occurred. Prediction of these fewer variations in bed topography in the first half has been among the hypotheses presented in this study;

- Since the flow at the first half of the downstream bend was oriented toward the inner bank, the maximum sedimentation height for every U/Uc value also occurred at a distance from 0 to $5 \%$ from the inner bank. Increasing $\mathrm{U} / \mathrm{Uc}=0.8$ to 0.98 changed the location of the maximum sedimentation from the 195-degree angle to the 245-degree angle;

- Based on the initial hypotheses, for every $\mathrm{U} / \mathrm{Uc}$ at the upstream bend, the maximum scour occurred at a distance of $5 \%$ of the channel width from the outer bank and within the range of 178 to 180 degrees. Increasing U/Uc from 0.89 to $0.92,0.95$, and 0.98 at this bend, respectively, increased the maximum scour depth by factors of 4.3 , 4.4, and 15;

- Increasing $\mathrm{U} / \mathrm{Uc}_{\mathrm{c}}$ from 0.8 to $0.84,0.86,0.89,0.92,0.95$, and 0.98 at the downstream bend, respectively, increased the maximum scour depth by factors of 1.5, 2.5, 5, 10, 12, and 26, and the maximum sedimentation height by factors of $3,10,23,48,49$, and 56;

- Contrary to the hypothesis stating the maximum scour development at the outer bend, it was observed that for $\mathrm{U} / \mathrm{Uc}$ values ranging from 0.92 to 0.98 , the maximum scour occurred at a distance of $5 \%$ of the inner bend within 185 to 195 degrees. However, for $\mathrm{U} / \mathrm{Uc}$ values ranging from 0.8 to 0.89 , the maximum scour occurred at a distance of 30 to $40 \%$ of the channel width within the range of 270 to 275 degrees.

Author Contributions: N.M.: Designing and constructing the laboratory setup; Data Collection; Methodology; Visualization; Writing-Original Draft Preparation; Resources; Formal Analysis; Software; Investigation. S.H.M.-J.: Supervision; Conceptualization; Project Administration; Formal analysis; Validation; Writing-Review and Editing. M.V.: Supervision; Designing the laboratory setup; Conceptualization; Methodology; Project Administration; Formal Analysis; Validation; Writing-Review and Editing. A.K.: Advising, Formal Analysis; Conceptualization; Investigation; Validation; Writing-Review and Editing. All authors have read and agreed to the published version of the manuscript.

Funding: This research received no external funding.

Institutional Review Board Statement: Not applicable.

Informed Consent Statement: Not applicable.

Conflicts of Interest: The authors declare no conflict of interest.

\section{References}

1. Randle, T.J. Use of Multidimensional Models to Investigate Boundary Shear Stress through Meandering River Channels. Water 2020, 12, 3506. [CrossRef]

2. Bertalan, L.; Novák, T.J.; Németh, Z.; Rodrigo-Comino, J.; Kertész, Á.; Szabó, S. Issues of meander development: Land degradation or ecological value? The example of the Sajó River, Hungary. Water 2018, 10, 1613. [CrossRef]

3. Garcia, J.T.; Castillo, L.G.; Haro, P.L.; Carrillo, J.M. Occlusion in Bottom Intakes with Circular Bars by Flow with Gravel-Sized Sediment. An Experimental Study. Water 2018, 10, 1699. [CrossRef]

4. Das, V.K.; Barman, K.; Roy, S.; Chaudhuri, S.; Debnath, K. Near bank turbulence of a river bend with self similar morphological structures. Catena 2020, 191, 104582.

5. Shields, A. Application of the Theory of Similarity and Turbulence Research to the Bedload Movement; Transl. QM Saleh. Mitt. Preuss. Vers. Wasserbau Schiffbau: Berlin, Germany, 1936.

6. Dey, S.; Papanicolaou, A. Sediment threshold under stream flow: A state-of-the-art review. KSCE. J. Civ. Eng. 2008, 12, 45-60. [CrossRef] 
7. Kramer, H. Sand mixtures and sand movement in fluvial model. Trans. Am. Soc. Civ Eng. 1935, 100, 798-838. [CrossRef]

8. Bagnold, R.A. The nature of saltation and of 'bed-load'transport in water. Proc. R. Soc. Lond. A Math. Phys. Sci. 1973, 332, 473-504.

9. Neill, C.R. Note on initial movement of coarse uniform bed-material. J. Hydraul. Res. 1968, 6, 173-176. [CrossRef]

10. Lavelle, J.W.; Mofjeld, H.O. Do critical stresses for incipient motion and erosion really exist? J. Hydraul. Eng. 1987, 113, 370-385. [CrossRef]

11. Yen, C.L.; Lee, K.T. Bed topography and sediment sorting in channel bend with unsteady flow. J. Hydraul. Eng. 1995, 121, 591-599. [CrossRef]

12. Dey, S.; Debnath, K. Influence of streamwise bed slope on sediment threshold under stream flow. J. Irrig. Drain. E. 2000, 126, 255-263. [CrossRef]

13. Xu, D.; Bai, Y. Experimental study on the bed topography evolution in alluvial meandering rivers with various sinuousnesses. J. Hydro-Environ. Res. 2013, 7, 92-102. [CrossRef]

14. Mohtar, W. Threshold criteria for incipient grain motion with turbulent fluctuations on a horizontal bed. Sains. Malays. 2015, 44, 147-153. [CrossRef]

15. Liu, X.; Zhou, Q.; Huang, S.; Guo, Y.; Liu, C. Estimation of flow direction in meandering compound channels. J. Hydrol. 2018, 556, 143-153. [CrossRef]

16. Safari, M.J.S.; Aksoy, H.; Unal, N.E.; Mohammadi, M. Experimental analysis of sediment incipient motion in rigid boundary open channels. Environ. Fluid. Mech. 2017, 17, 1281-1298. [CrossRef]

17. Núñez-González, F.; Rovira, A.; Ibàñez, C. Bed load transport and incipient motion below a large gravel bed river bend. Adv . Water Resour. 2018, 120, 83-97. [CrossRef]

18. Qin, C.; Shao, X.; Xiao, Y. Secondary Flow Effects on Deposition of Cohesive Sediment in a Meandering Reach of Yangtze River. Water 2019, 11, 1444. [CrossRef]

19. Taye, J.; Kumar, B. Experimental study on near-bed flow turbulence of sinuous channel with downward seepage. In Proceedings of the Institution of Civil Engineers-Water Management; Thomas Telford Ltd.: London, UK, 2020.

20. Azarisamani, A.; Keshavarzi, A.; Hamidifar, H.; Javan, M. Effect of Rigid Vegetation on Velocity Distribution and Bed Topography in a Meandering River with a Sloping Bank. Arab. J. Sci. Eng. 2020, 45, 8633-8653. [CrossRef]

21. Akbari, M.; Vaghefi, M.; Chiew, Y.M. Effect of T-shaped spur dike length on mean flow characteristics along a 180-degree sharp bend. J. Hydrol. Hydromech. 2021, 69, 98-107. [CrossRef]

22. Moghaddassi, N. Experimental Study of Scour Pattern around Bridge Piers in Meander. Ph.D. Thesis, Islamic Azad University, Science and Research Branch, Tehran, Iran, 2021.

23. Leschziner, M.A.; Rodi, W. Calculation of strongly curved open channel flow. J. Hydraul. Div. 1979, 105, 1297-1314. [CrossRef]

24. Raudkivi, A.J.; Ettema, R. Clear-water scour at cylindrical piers. J. Hydraul. Eng. 1983, 109, 338-350. [CrossRef]

25. Ben Mohammad Khajeh, S.; Vaghefi, M.; Mahmoudi, A. The scour pattern around an inclined cylindrical pier in a sharp 180-degree bend: An experimental study. Int. J. River. Basin. Manag. 2017, 15, 207-218. [CrossRef]

26. Chiew, Y.M. Scour protection at bridge piers. J. Hydraul. Eng. 1992, 118, 1260-1269. [CrossRef]

27. Termini, D. Experimental observations of flow and bed processes in large-amplitude meandering flume. J. Hydraul. Eng. 2009, 135, 575-587. [CrossRef]

28. Vaghefi, M.; Motlagh, M.J.T.N.; Hashemi, S.S.; Moradi, S. Experimental study of bed topography variations due to placement of a triad series of vertical piers at different positions in a 180 bend. Arab. J. Geosci. 2018, 11, 102-115. [CrossRef]

29. Asadollahi, M.; Vaghefi, M.; Akbari, M. Effect of the position of perpendicular pier groups in a sharp bend on flow and scour patterns: Numerical simulation. J. Braz. Soc. Mech. Sci. 2020, 42, 422-437. [CrossRef]

30. Solati, S.; Vaghefi, M.; Behroozi, A.M. Effect of Duration and Pattern of Hydrographs on Scour around Pier in Sharp Bend Under Incipient Motion and Live Bed Conditions. Int. J. Civ. Eng. 2021, 19, 51-65. [CrossRef]

31. Ben Meftah, M.; De Padova, D.; De Serio, F.; Mossa, M. Secondary Currents with Scour Hole at Grade Control Structures. Water 2021, 13, 319. [CrossRef]

32. Vaghefi, M.; Akbari, M.; Fiouz, A.R. An experimental study of mean and turbulent flow in a 180 degree sharp open channel bend: Secondary flow and bed shear stress. KSCE. J. Civ. Eng. 2016, 20, 1582-1593. [CrossRef]

33. Akbari, M.; Vaghefi, M. Experimental investigation on streamlines in a $180^{\circ}$ sharp bend. Acta Sci. Technol. 2017, 39, 425-432. 